\title{
Oxygen minimum zones in the eastern tropical Atlantic and Pacific Oceans
}

\author{
Johannes Karstensen*, Lothar Stramma, and Martin Visbeck \\ Leibniz-Institut für Meereswissenschaften an der Universität Kiel, \\ Düsternbrooker Weg 20, 24105 Kiel, Germany
}

Status: 2 May 07

*corresponding author:

Johannes Karstensen

Leibniz-Institut für Meereswissenschaften (IFM-GEOMAR)

Düsternbrooker Weg 20

24105 Kiel, Germany

tel. $+49-431-600-4156$

fax $+49-431-600-4102$

e-mail:jkarstensen@ifm-geomar.de 


\section{Abstract}

Within the eastern tropical oceans of the Atlantic and Pacific basin vast oxygen minimum zones (OMZ) exist in the depth range between 100 to $900 \mathrm{~m}$. Minimum oxygen values are reached at 300 to $500 \mathrm{~m}$ depth which in the eastern Pacific become suboxic (dissolved oxygen content $<4.5 \mu \mathrm{mol} \mathrm{kg}{ }^{-1}$ ) with dissolved oxygen concentration of less than $1 \mu \mathrm{mol} \mathrm{kg}{ }^{-1}$. The OMZ of the eastern Atlantic is not suboxic and has relatively high oxygen minimum values of about $17 \mu \mathrm{mol} \mathrm{kg} \mathrm{kg}^{-1}$ in the South Atlantic and more than $40 \mu \mathrm{mol} \mathrm{kg}{ }^{-1}$ in the North Atlantic. About 20\% (40\%) of the North Pacific volume is occupied by an $\mathrm{OMZ}$ when using $45 \mu \mathrm{mol} \mathrm{kg}-1$ (or $90 \mu \mathrm{mol} \mathrm{kg}{ }^{-1}$ respectively) as an upper bound for $\mathrm{OMZ}$ oxygen concentration for ocean densities lighter than $\sigma_{\theta}<27.2 \mathrm{~kg} \mathrm{~m}^{-3}$. The relative volumes reduce to less than half for the South Pacific $(7 \%$ and $13 \%$, respectively). The abundance of OMZ's are considerably smaller ( $1 \%$ and $7 \%$ ) for the South Atlantic and only $\sim 0 \%$ and $5 \%$ for the North Atlantic. Thermal domes characterized by upward displacements of isotherms located in the northeastern Pacific and Atlantic and in the southeastern Atlantic are co-located with the centres of the OMZ's, however, they seem not directly involved in the generation of the OMZ's.

OMZ's are a consequence of a combination of weak ocean ventilation, which supplies oxygen, and respiration, which consumes oxygen. Oxygen consumption can be approximated by the apparent oxygen utilization (AOU). However, AOU scaled with an appropriate consumption rate (aOUR) gives a time, the oxygen age. Her we derive oxygen ages using climatological AOU data and an empirical estimate of aOUR. Averaging oxygen ages for main thermocline isopycnals of the Atlantic and Pacific Ocean exhibit an exponential increase with density without an obvious signature of the OMZ's. Oxygen supply originates from a surface outcrop area and can also be approximated by the turn-over time, that is the ratio of ocean volume to ventilating flux. The turn-over time corresponds well to the average oxygen ages for the well ventilated waters. However, in the density ranges of the suboxic OMZ's the turn-over time substantially increases. This indicates that reduced ventilation in the outcrop is directly related to the existence of suboxic OMZ's, however, they are not obviously related to enhanced consumption. The turn-over time suggests that the lower thermocline of the North Atlantic would be suboxic but at present this is compensated 
by the import of water from the well ventilated South Atlantic. The turn-over time approach itself is independent of details of ocean transport pathways. However, the geographical location of the $\mathrm{OMZ}$ is to first order determined by: i) the patterns of upwelling, either through Ekman or equatorial divergence, ii) the regions of general sluggish horizontal transport at the eastern boundaries, and iii) to a lesser extent to regions with high productivity as indicated through ocean color data.

subject keywords: oxygen minimum zones, water mass spreading, eastern tropical Atlantic, eastern tropical Pacific, suboxic, water age

regional terms: tropical Atlantic, eastern Atlantic, tropical Pacific, eastern Pacific 


\section{Contents:}

1. Introduction

2. Data and methods

2.1. The data sets

2.2. Methods

2.2.1 Conversion of oxygen units

2.2.2 Subduction rate estimate

2.2.3 Water age estimates

3. Description of the $\mathrm{OMZ}$ in the Atlantic and Pacific oceans

3.1. The OMZ in the Guinea Dome region

3.2. The OMZ in the Angola Dome region

3.3. The OMZ in the Costa Rica Dome region

3.4. The OMZ off Peru and Chile

4. Oxygen consumption and Oxygen supply

4.1 Oxygen consumption $\left(O_{2, \text { consumption }}\right)$

4.2 Oxygen supply $\left(O_{2, \text { transport }}\right)$

4.3 Combining supply and consumption: oxygen age and turn-over time

5. Atlantic-Pacific Comparison

6. Conclusions

Acknowledgements

References 


\section{Introduction}

Ventilation of the ocean's interior originates from the ocean surface where air-sea exchanges set water mass conditions and supply oxygen to the surface mixed layer. Large scale gradients of surface properties combined with ocean transport and mixing processes generate complex horizontal and vertical gradients of the interior ocean properties. Some properties, as dissolved oxygen content (referred to in the following as oxygen), have additional sources and sinks in the ocean interior which further modify their horizontal and vertical gradients compared to a 'transport only' distribution. For some properties, like oxygen, it is relevant to delineate the partitioning between contributions due to ocean ventilation/transport and those due to biogeochemical cycling.

Oxygen is a key parameter for biogeochemical cycles and as such a major player in the oceans carbon system (Bopp, LeQuéré, Heimann, Manning, \& Monfray, 2002) as well as the marine nitrogen cycle (Bange, Naqvi, \& Codispoti, 2005). Changes in marine oxygen levels have also been linked to the global climate system (Keeling, \& Garcia, 2002). Volumes of the interior ocean that are relatively poor in oxygen are often called oxygen minimum zones (OMZ's). OMZ's are presumed to have varied significantly in extend over geological times and possibly altered the ocean carrying capacity of carbon and nitrogen significantly (e.g. Meissner, Galbraith, \& Völker, 2005).

OMZ's are located in regions with specific characteristics in both, biogeochemical cycling and physical ocean ventilation. From the biogeochemical point of view the OMZ's are located in eastern boundary upwelling areas with high productivity and rather complex cycling of nutrients (e.g. Helly \& Levin, 2004). In respect to the physics of ocean ventilation OMZ's are seen as a consequence of minimal lateral replenishment of surface waters (Reid, 1965) since they are located in the so called 'shadow zones', unventilated by the basin scale wind-driven circulation (e.g. Luyten, Pedlosky, \& Stommel, 1983). The possible interplay of the two mechanisms, supply by ocean circulation and demand by ocean biogeochemistry makes understanding, modelling and prediction of OMZ's location, strength and in particular their temporal variability a challenging task. Model based scenarios of the "future ocean" predict an overall 
dissolved oxygen decline and consequent expansion of OMZ's under global warming conditions (e.g. Matear \& Hirst, 2003). However, even on seasonal to interannual time scales variability can be high: Helly \& Levin (2004) report $60 \%$ reduction in the sea floor area influenced by the eastern South Pacific OMZ $\left(<20 \mu \mathrm{mol} \mathrm{kg}^{-1}\right)$ off Peru and northern Chile during El Niño years. However, this can not be translated into a reduction of the oceans $\mathrm{OMZ}$ volume as most of the seafloor area is on the continental shelf break and an offshore retreat would detach the OMZ from the sea floor thus reducing its sea floor area extent substantially.

There is no agreed upon threshold in oxygen that defines an OMZ. However, three terms have been used to describe the overall oxygen conditions: anoxic, suboxic, and oxic. Anoxic waters have virtually no oxygen and high levels of sulfide are released into the water column. A prominent example is the Black Sea (Murray, Stewart, Kassakian, Krynytzky, \& DiJulio, 2005). If oxygen is detectable but below about 4.5 $\mu \mathrm{mol} \mathrm{kg}{ }^{-1}\left(0.1 \mathrm{ml} \mathrm{l}^{-1}\right)$ the water is called suboxic (Warren, 1995; Morrison, Codispoti, Smith, Wishner, Flagg et al., 1999). This threshold is rather well defined as oxygen derived from nitrate is used for the remineralization of organic matter. During remineralization under suboxic conditions nitrite is released to the water column and nitrate removed (e.g. Gruber \& Sarmiento, 1997; Bange et al., 2005). We will draw some attention to the suboxic threshold as it marks a real change in the environment. There are more loosely defined thresholds for OMZ regions: Helly \& Levin (2004) used a threshold of $20 \mu \mathrm{mol} \mathrm{kg} \mathrm{kg}^{-1}\left(0.5 \mathrm{ml} \mathrm{l}^{-1}\right)$ in their global analysis on seafloor OMZ environments which however excludes the North Atlantic OMZ that has rather high oxygen levels. For our analysis we used three oxygen thresholds OMZ: The suboxic level $\left(4.5 \mu \mathrm{mol} \mathrm{kg} \mathrm{kg}^{-1}\right)$, a more stringent $45 \mu \mathrm{mol} \mathrm{\textrm {kg } ^ { - 1 }}$ and a more relaxed level of $90 \mu \mathrm{mol} \mathrm{kg} \mathrm{kg}^{-1}$.

The maintenance of suboxic (and anoxic) conditions involves rather complex biogeochemical processes and will not be considered explicitly. This is justified, as the volume of suboxic water is rather small compared to the oxic waters with the $\mathrm{OMZ}$ thresholds given above. However, as will be discussed later the admixture of water affected through suboxic consumption can have an significant influence on oxic waters for example by their nitrite levels (Gruber \& Sarmiento, 1997). 
In general OMZ's exist in the eastern part of the tropical oceans at the Central and Intermediate Water depth range within 100 to $900 \mathrm{~m}$ depth (Fig. $1 \mathrm{c}$ ). Figure 1 shows two relevant aspects of the global oxygen distribution. First the oxygen concentration at a depth level of $400 \mathrm{~m}$ (Fig. 1 a) highlights the general east-west gradients in the Pacific and Atlantic Oceans as well as the north south gradient especially strong in the Indian Ocean.

The minimum oxygen concentrations above the depth of $1400 \mathrm{~m}$ clearly shows the differences between the three basins with the North Atlantic being much better ventilated (Fig. 1 b). In the Pacific Ocean there are two large OMZ regions, one in the North Pacific off Central America and one in the South Pacific off Peru and Chile both reaching far into the central Pacific. Here the minimum oxygen values may even reach the suboxic level with values below $4.5 \mu \mathrm{mol} \mathrm{kg}^{-1}\left(0.1 \mathrm{ml} \mathrm{l}^{-1}\right)$ (Fig. $\left.1 \mathrm{~b}\right)$. Although more oxygenated with minimum values on the order of 20 to $40 \mu \mathrm{mol} \mathrm{kg}{ }^{-1}$ the spatial distribution in the Atlantic is similar to that in the Pacific with the OMZ on the eastern side to the north and south of the equator. As the direct ventilation of North Pacific waters is confined to densities $<26.6 \mathrm{~kg} \mathrm{~m}^{-3}$ (Suga et al., this issue) the North Pacific has a much more intense OMZ than all other oceans. In contrast, the subtropical southern hemisphere oceans south of $20^{\circ} \mathrm{S}$ are typically well ventilated with oxygen above $90 \mu \mathrm{mol} \mathrm{kg} \mathrm{kg}^{-1}$, as a consequence of intense water mass formation over a wide outcrop area (Karstensen \& Quadfasel, 2002). The minimum oxygen concentration in the Indian Ocean in this climatology is located in the northeast part of the Arabian Sea.

Strong interannual to decadal time variations of oxygen exists in the upper $100 \mathrm{~m}$ of the world ocean. There, relatively small linear trends are superimposed on large decadalscale fluctuations (Garcia, Boyer, Levitus, Locarnini, \& Antonov, 2005). The lowest oxygen content in the late-1950s was followed by high content in the mid-1980s and by low content in the late-1990s. In the upper thermocline of the northeast subtropical Pacific between 1980 and 1997 an increase of 20-25\% apparent oxygen utilization (AOU) was described (Emerson, Mecking, \& Abell, 2001). The solubility of oxygen is negatively correlated with temperature (Weiss, 1970) but Garcia et al. (2005) could not find a consistent oxygen-to-heat relation that satisfactorily explains the oxygen content 
changes for all time periods. This work, however, will focus on the time mean situation based on data observed mainly during the last 20 years.

In the eastern tropical Atlantic and Pacific thermocline domes (marked by white crosses in Fig. 1 a) are present and cover mainly the Central Water layer. These domes are permanent, quasi-stationary features on the eastern side of thermal ridges extending zonally across the ocean basins. The domes are characterized by upward displacements of isotherms in the thermocline layers down to depths of more than $300 \mathrm{~m}$. The domes are called the Guinea Dome in the tropical North Atlantic (e.g. Siedler, Zangenberg, Onken, \& Morliere, 1992), the Angola Dome in the South Atlantic (e.g. Mazeika, 1968) and the Costa Rica Dome in the North Pacific (e.g. Fiedler, 2002). Based on wind stress, water mass propertied and ocean current fields it has been speculated that a Peru Dome should exist at $8^{\circ} \mathrm{S}, 85^{\circ} \mathrm{W}$ (Siedler et al., 1992), however such a dome could not be identified as a significant oceanographic feature in the climatological database.

In the Indian Ocean the $\mathrm{OMZ}$ is located mainly in the northern hemisphere within the Arabian Sea and Bay of Bengal. Very low oxygen values indicate a slow renewal rate of thermocline waters in the northern Indian Ocean (Tomczak \& Godfrey, 1994). In the eastern Indian Ocean a weak OMZ reaches across the equator off Indonesia. As in the

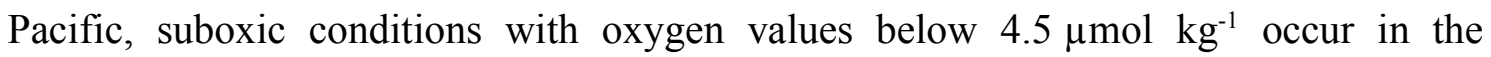
Arabian Sea and denitrification has been observed (e.g. Howell, Doney, Fine, \& Olson, 1997). Indian Central Water (ICW) and Australasian Mediterranean Water (AAMW) occupy the thermocline of the Indian Ocean. AAMW is a tropical water mass derived from Pacific Ocean Central Water with intense modifications during transit through the Indonesian Sea (Australasian Mediterranean Sea). The rapid inflow of AAMW into the Indian Ocean produces one of the strongest frontal systems of the world ocean's thermocline at about $15^{\circ} \mathrm{S}$. Oxygen values are fairly uniform south of the front (You \& Tomczak, 1993), suggesting swift recirculation of ICW in the subtropical gyre. Due to the front a transition into the northern hemisphere is confined mainly to the the western boundary current (Quadfasel \& Schott, 1982). The transition is accompanied by a rapid decrease in oxygen indicating only sluggish ventilation. The decrease in oxygen values does not continue into the Bay of Bengal and as a consequence denitrification has not been found (Howell et al., 1997). 
Due to the distribution of the continents the Indian Ocean behaves different with regard to circulation and water mass distribution with significanted consequences for the regional OMZ distribution when compared to the Pacific and Atlantic oceans. As the OMZ's in the Atlantic and Pacific have similar patterns but different strength we will focus our work on those two basins. In the following we quantify the OMZ's in volume and extent and identify critical physical processes that are responsible to maintain the low oxygen levels.

\section{Data and Methods}

\subsection{The data sets}

Three categories of data have been used in this study:

- synoptic data from individual cruises

- gridded observational data

- output from a numerical model that assimilates observational data

In the descriptive part of the paper a number of synoptic hydrographic sections are discussed which have been collected within WOCE and CLIVAR (Climate Variability and Predictability). The CLIVAR hydrographic section data is available through the CLIVAR and Carbon Hydrographic Data Office (CCHDO). An oxygen/ADCP-data section along $28^{\circ} \mathrm{W}$ recorded in May 2003 by $R V$ Sonne will also be presented as well.

Characteristics of the individual oceans OMZ (depth range, density range, lowest oxygen concentration) and oxygen utilization rates are derived using hydrographic, oxygen, chlorofluorocarbon $\mathrm{CFC}-11$ age (CFC-age), and conventional radiocarbon age (CR-age) data compiled within the Global Ocean Data Analysis Project (GLODAP; Sabine, Key, Kozyr, Feely, Wanninkhof et al., 2005). The GLODAP data is a merged data-set from bottle data collected during WOCE (World Ocean Circulation Experiment) and complemented with data from the Joint Global Ocean Flux Study 
(JGOFS), and from the NOAA Ocean-Atmosphere Exchange Study (OACES).

A climatology is used to estimate the intensity and the extend/volume of the OMZ's and to derive oxygen ages. We choose the gridded climatology of temperature, salinity, and oxygen produced in the former Special Analysis Centre (WHP SAC) of the WOCE Hydrographic Programme (WHP) and based on numerous global hydrographic surveys (WHP-SAC; Gouretski \& Jahnke, 1998). The WHP-SAC data is interpolation along neutral surfaces to a $1 \times 1$ degree grid with a subsequent interpolation to 45 vertical levels (27 levels in the upper 1500m).

To obtain information on the transport within and into the thermocline version 1.4 of the Simple Ocean Data Assimilation (SODA; Carton, Chepurin, \& Giese, 2000; Carton, $\&$ Giese, submitted) output was used. SODA is an ongoing effort to develop reanalysis of the upper ocean for the benefit of climate studies as a complement to atmospheric reanalysis. SODA assimilates virtually all available hydrographic profile data as well as ocean station data, moored temperature and salinity time series, and surface temperature and salinity observations of various types. In addition two satellite data sets are included, sea-surface temperature from nighttime satellite thermal images and sea level data from a number of satellite altimeter. The underlying model is an eddypermitting version of Parallel Ocean Program model with 40 levels in the vertical and $0.4 \times 0.25$ degree displaced pole grid. The model is optimized, in respect to horizontal and vertical resolution, to simulate upper ocean processes. For convenience the data is mapped to a $0.5 \times 0.5$ degrees grid and is available in monthly fields. We use 10-year monthly means, as well as one single climatological mean state based on averaging data from 1992 to 2001.

\subsection{Methods}

\subsubsection{Conversion of oxygen units}

According to WOCE recommendations following SI-standards dissolved oxygen should be discussed in units of $\mu \mathrm{mol} \mathrm{kg}{ }^{-1}$ while in older data sets as well as in the literature 
oxygen is often presented in units of $\mathrm{ml} \mathrm{l}^{-1}$. Therefore, both units are used when discussing our results in the context of other published work. Oxygen concentrations in $\mathrm{ml} \mathrm{l}^{-1}$ is converted in most cases to units of $\mu \mathrm{mol} \mathrm{kg}{ }^{-1}$ by: $\mathrm{O}_{2}\left(\mu \mathrm{mol} \mathrm{kg}{ }^{-1}\right)=44.6596$ $\left(\mu \mathrm{mol} \mathrm{ml}{ }^{-1}\right) * \mathrm{O}_{2}\left(\mathrm{ml} \mathrm{l}^{-1}\right) / \rho_{\mathrm{sw}}\left(\mathrm{kg} \mathrm{m}^{-3}\right)$, where $\rho_{\mathrm{sw}}$ is the density of seawater at the temperature at which the oxygen sample was taken (value 44.6596 from UNESCO, 1986). For a density of $1026.9 \mathrm{~kg} \mathrm{~m}^{-3}$, the factor of 44.6596 reduces to 43.4897 . In a few instances we needed to convert $\mathrm{ml} \mathrm{l}^{-1}$ to $\mu \mathrm{mol} \mathrm{kg}^{-1}$ without knowing $\rho_{\mathrm{sw}}$, and we used $1026.9 \mathrm{~kg} \mathrm{~m}^{-3}$ instead which is over large parts associated with the OMZ's. The error introduced by this approximation is at maximum $1 \%$ on the calculated oxygen in

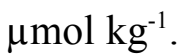

\subsubsection{Subduction rate estimate}

Part of our study is based on the water mass formation in the outcrop of the isopycnals that hosts the OMZ. The water mass formation (subduction rates) is calculated based on a method first applied by Marshall, Nurser, \& Williams (1993). In brief, the vertical velocities at the base of the winter mixed layer are separated into an Ekman pumping term, with some correction in respect to meridional transport in the mixed layer, and a lateral transport (see Marshall et al., 1993; Karstensen \& Quadfasel, 2002 for further details of the method). One essential point in the calculations is to determine the deepest mixed layer depth, typical late winter, as this is from were subduction originates. We used a $0.125 \mathrm{~kg} / \mathrm{m}^{3}$ increase in density in reference to the surface $(5 \mathrm{~m}$ depth) density to estimate the mixed layer depth. Mixed layer topography is derived from the 10 year averaged SODA winter (southern hemisphere: September; northern hemisphere: March) hydrographic data. The Ekman pumping is derived from the 10 year average wind stress data that was used to force the SODA model. All velocity information which are needed to estimate the magnitude of the lateral induction through the tilted mixed layer base as well as for the correction of the Ekman pumping are directly available as SODA model output. 


\subsubsection{Water age estimates}

Another quantity of interest for the ventilation of the interior ocean is the 'age' of the water, which stands for the time that it takes a water parcel to spread from the outcrop region, where it left the mixed layer, to a point in the ocean interior (e.g. Bolin \& Rhode, 1973; Tomczak, 1999; Khatiwala, Visbeck \& Schlosser, 2001, Haine \& Hall, 2002). In the presence of mixing there is not a single 'age' but rather a multitude of pathways of composing source waters (Tomczak, 1999) with individual source water ages. The use of a combination of age tracers may resolve different source water ages and may give for each sample what is called an 'age spectrum' rather than only one single (average) age (e.g. Bolin \& Rohde, 1973; Haine \& Hall, 2002). However, for the purpose of this work we will use the first mode of such a transit time distribution as a proxy for the most likely 'age'. We will use water ages derived from three different tracers: chlorofluorocarbon $(\mathrm{CFC}),{ }^{14} \mathrm{C}$ and oxygen. A brief introduction into the three different types of age determination based on this tracers is given in the following. Further details will be given in the respective chapters where the ages are used.

CFC-ages are provided with the GLODAP data set. They are derived by first converting an observed CFC concentration into an atmospheric equivalent making use of the temperature and salinity dependent CFC solubility function (Warner \& Weiss, 1985). Assuming 100\% saturation of surface water and no mixing effects the atmospheric equivalent concentration equals the atmospheric concentration at the moment the water left the mixed layer. Comparing the atmospheric equivalent concentration with the reconstructed atmospheric time history of the tracer concentration (Walker, Weiss, \& Salameh, 2000) gives, as long as the concentration increases with time, one particular year were both match. This is assumed to be the year the water left the surface. The CFC age finally is the difference between the date the observation was taken and the formation date, based on the atmospheric equivalent. The CFC-ages from the GLODAP data set are used here to derive oxygen consumption rates (chapter 4.1).

Based on the ${ }^{14} \mathrm{C}$ content so called 'conventional radiocarbon ages' (CR-ages) can be derived. As for the CFC ages, the CR-ages are provided with the GLODAP data set. 
CR-ages are obtained from measuring the residual radioactivity of a water sample and comparing it with the activity of modern and background samples and using the radiocarbon decay equation (half-live time of about 5700 years). Through their natural occurrence and long half-live CR-ages cover long ventilation time ranges. However, they suffer from 'contamination' of the surface water isotopic composition through the industrialization (so called 'Suess effect') and the nuclear bomb testing in the 1950's. Therefore CR-ages are without specific effort in separating these effects (e.g. Sonnerup, Quay, \& Bullister, 1999) only 'valid' for water ages for long time scales say at and below the level of the intermediate water. The GLODAP CR-ages are not corrected for the Suess effect and we will use them here only as a boundary condition when deriving oxygen consumption rates at the base of the thermocline (chapter 4.1).

The oxygen age is based on knowledge about the oxygen that was removed from a water parcel during its spreading in the interior and the time rate of oxygen removal. For the amount of oxygen removed we will use here the apparent oxygen utilization (AOU), which is the difference between in-situ oxygen and the 'theoretical' saturation value (e.g. Weiss, 1970) assuming 100\% saturation at the surface. In general AOU gives the time integral of all processes that influence the oxygen content that is removal as well as production. However, oxygen production is confined to photosynthesis in the euphotic zone and influences water parcels mainly on the seasonal time scale and therefore it is neglected here. For the bulk of the thermocline oxygen removal/ consumption is either through remineralization or through denitrification. The rate of oxygen consumption rapidly drops when entering the denitrification regime (as virtually no oxygen is left to be removed). Therefore at least two different oxygen consumption rates would be needed to fully describe the removal. However, ocean regions where denitrification takes place are small (see Fig. $1 \mathrm{~b}$ ) and we concentrate on the consumption during remineralization only. Using AOU as the amount of oxygen that was removed and tracer based water ages the removal rate is called 'apparent oxygen utilization rate' (aOUR) (e.g. Jenkins, 1987; Karstensen \& Tomczak, 1998; Sonnerup et al., 1999; Mecking, Warner, \& Bullister, 2006). At first we derive aOUR based on the GLODAP data set AOU and CFC-ages and CR-ages (chapter 4.1). Next a best fit through the aOUR will be used in combination with the WHP-SAC data AOU to derive oxygen ages. This is further discussed in chapter 4.3. 


\section{Description of the $\mathrm{OMZ}$ in the Atlantic and Pacific oceans}

\subsection{The OMZ in the Guinea Dome region}

In the eastern North Atlantic the core of the oxygen minimum is located in the 'shadow zone' at the eastern boundary and comprises the Central Water $\left(\sigma_{\theta}=25.8\right.$ to $\left.27.1 \mathrm{~kg} \mathrm{~m}^{-3}\right)$ and the Antarctic Intermediate Water (AAIW; $\sigma_{\theta}=27.1 \mathrm{kgm}^{-3}$ to $\sigma_{1}=32.15 \mathrm{~kg} \mathrm{~m}^{-3}$ ) layers (Stramma, Hüttl, \& Schafstall, 2005). The OMZ is located between the equatorial current system and the North Equatorial Current (NEC). The Guinea Dome is centred at $9^{\circ} \mathrm{N}, 25^{\circ} \mathrm{W}$ in boreal summer and $10.5^{\circ} \mathrm{N}, 22^{\circ} \mathrm{W}$ in boreal winter (Siedler et al., 1992). The NEC and the equatorial currents together with the Guinea Dome in the eastern tropical North Atlantic form a cyclonic tropical gyre (e.g. Stramma \& Schott, 1999; their Fig. 5). The boundary between the NEC transporting North Atlantic Central Water (NACW) and the tropical gyre carrying South Atlantic Central Water (SACW) is the Cape Verde Frontal Zone at about $16^{\circ} \mathrm{N}$ and $20^{\circ} \mathrm{N}$ near Africa. The Cape Verde Frontal Zone is tilted from north to south with increasing depths, as SACW overrides NACW (Tomczak, 1984a).

On a meridional section made in July/August 2003 at about $25^{\circ} \mathrm{W}$ the oxygen minimum is located at 400 to $500 \mathrm{~m}$ depth close to the isopycnal $\sigma_{\theta}=27.1 \mathrm{~kg} \mathrm{~m}^{-3}$ representing the water mass boundary between Central Water and AAIW (Stramma et al., 2005; their Fig. 2). A strong oxycline at less then $100 \mathrm{~m}$ depth separates the oxygen rich tropical surface water from the oxygen poor Central Water. Oxygen concentrations of less then $100 \mu \mathrm{mol} \mathrm{kg} \mathrm{kg}^{-1}$ reach from the oxycline to a maximum depth of $850 \mathrm{~m}$ at about $13^{\circ} \mathrm{N}$. The lowest oxygen values of less then $50 \mu \mathrm{mol} \mathrm{kg}-1$ were located between $10.5^{\circ} \mathrm{N}$ and $12.5^{\circ} \mathrm{N}$ near $400 \mathrm{~m}$ depth.

A zonal $R V$ Meteor section crossing the Atlantic at about $10^{\circ} \mathrm{N}$ was carried out within the Surface Ocean Lower Atmosphere Study (SOLAS) program in October and November 2002. Wallace \& Bange (2004) presented for this section the nitrate and oxygen distribution from closely spaced bottle data for the upper $600 \mathrm{~m}$. They found an oxygen minimum of less than $50 \mu \mathrm{mol} \mathrm{kg}{ }^{-1}$ east of $28^{\circ} \mathrm{W}$ centred near $400 \mathrm{~m}$ depth. 
The vertical extent of the OMZ of less than $50 \mu \mathrm{mol} \mathrm{kg}{ }^{-1}$ was about $150 \mathrm{~m}$. Wallace \& Bange (2004) further described for the eastern basin a less-pronounced oxygen minimum at the base of the thermocline at 60 to $150 \mathrm{~m}$ depth. This shallow oxygen minimum may be caused by enhanced remineralization in a region with enhanced biological productivity and a shallow mixed layer. After finishing the $10^{\circ} \mathrm{N}$ section the ship traveled southward off Africa, and a low oxygen bottle measurement of $40.3 \mu \mathrm{mol} \mathrm{kg}{ }^{-1}$ at $400 \mathrm{~m}$ depths was observed at $9^{\circ} 18^{\prime} \mathrm{N}, 1^{\circ} 00^{\prime} \mathrm{W}$. Taking the GLODAP bottle data-set as an additional reference (Table 1), no oxygen values lower then $40 \mu \mathrm{mol} \mathrm{kg}{ }^{-1}$ have been observed in the eastern tropical North Atlantic. Hence, the $\mathrm{OMZ}$ in the North Atlantic is currently far from being suboxic $\left(<4.5 \mu \mathrm{mol} \mathrm{kg}{ }^{-1}\right)$.

A section located to the south of the centre of the Guinea Dome OMZ at $7^{\circ} 30^{\prime} \mathrm{N}$ in February/March 1995 (Arhan, Mercier, Bourles \& Gouriou, 1998) shows the westward extend of the $\mathrm{OMZ}$ with oxygen values less than $70 \mu \mathrm{mol} \mathrm{kg}{ }^{-1}$ to $27^{\circ} \mathrm{W}$ (Fig. 2). The oxygen minimum is located slightly above the isopycnal $27.1 \mathrm{~kg} \mathrm{~m}^{-3}$, hence just above the boundary of Central Water and AAIW. Oxygen values of less than $50 \mu \mathrm{mol} \mathrm{kg}^{-1}$ are seen on this section only east of $18^{\circ} \mathrm{W}$ near Africa. A mid-depth oxygen minimum is present also on the western side of the complete $7^{\circ} 30^{\prime} \mathrm{N}$ section, however a minimum of less than $100 \mu \mathrm{mol} \mathrm{kg}{ }^{-1}$ was only observed east of $37^{\circ} \mathrm{W}$ (Arhan et al., 1998; their Fig. 5). As described already for the $10^{\circ} \mathrm{N}$ section the less pronounced oxygen minimum at less than $100 \mathrm{~m}$ depths is present east of $26^{\circ} \mathrm{W}$ (Fig. 2) in the upper part of the $7^{\circ} 30^{\prime} \mathrm{N}$ section and is likely a product of consumption during enhanced remineralization at the base of the mixed layer.

No section with well calibrated CTD-oxygen profiles crossing the centre of the OMZ is available from the data centres. The $7^{\circ} 30^{\prime} \mathrm{N}$ section (Fig. 2) is located well to the south of the centre of the OMZ. The bottle data of the $10^{\circ} \mathrm{N}$ section (Wallace $\&$ Bange, 2004, their Fig. 2) crosses quite well the centre of the $\mathrm{OMZ}$ and the lowest oxygen values reached are higher then $40 \mu \mathrm{mol} \mathrm{kg}{ }^{-1}$. An inspection of the oxygen bottle data of a $R V$ Meteor section carried out in February 1989 along $14.5^{\circ} \mathrm{N}$ east of $44^{\circ} \mathrm{W}$ (CTD section used in Klein, Molinari, Müller, \& Siedler, 1995) showed only a small region of oxygen values of less then $50 \mu \mathrm{mol} \mathrm{kg}-1$ east of $20^{\circ} \mathrm{W}$ close to the shelf. This may indicate that the $\mathrm{OMZ}$ has weakened (being less oxygenated at $14.5^{\circ} \mathrm{N}$ ). 
The uptake of CFC by the ocean can be a good indicator for the ventilation of the upper ocean and in deep convection areas. We prefer to discuss the CFC uptake in the OMZ in reference to the CFC inventory rather referring to published work on CFC ages, as no coherent global CFC age analysis is available currently. A global CFC-11 water column inventory was derived from WOCE observational data by Willey, Fine, Sonnerup, Bullister, Smethie, \& Warner (2004). On a global scale, Willey et al. (2004) estimated that the CFC inventory represents by $82 \%$ the uptake of the $1000 \mathrm{~m}$ of the ocean. The tropical eastern North Atlantic thermocline is well ventilated (high inventory) up to about $30^{\circ} \mathrm{N}$. The smallest inventory in the North Atlantic is found at about $10^{\circ} \mathrm{N}$ but still the inventory here is higher than at $10^{\circ} \mathrm{S}$ in the Atlantic or $10^{\circ} \mathrm{N} / 10^{\circ} \mathrm{S}$ in the Pacific emphasizing again the well ventilated character of the North Atlantic.

The North Equatorial Counter- and Undercurrents at 3 to $6^{\circ} \mathrm{N}$ are major oxygen sources for the Central Water layer of the low-oxygen regions in the northeastern tropical Atlantic (Stramma et al., 2005). A second, northern North Equatorial Countercurrent (nNECC) band exists at 8 to $10^{\circ} \mathrm{N}$. The nNECC carries oxygen rich water from the southern hemisphere eastward but with an admixture of water from the northern hemisphere. In the AAIW layer the Northern Intermediate Countercurrent (e.g. Stramma, Fischer, Brandt, \& Schott, 2003) acts as oxygen source for the oxygen minimum zone (Stramma et al., 2005).

\subsection{The OMZ in the Angola Dome region}

For the South Atlantic Mercier, Arhan and Lutjeharms (2003) define the isopycnals $\sigma_{\theta}=26.2$ to $27.05 \mathrm{~kg} \mathrm{~m}^{-3}$ as boundaries for Central Water and $\sigma_{\theta}=27.05 \mathrm{~kg} \mathrm{~m}^{-3}$ to $\sigma_{1}=32.1 \mathrm{~kg} \mathrm{~m}^{-3}$ for AAIW. Similar to the North Atlantic a dome exists in the tropical South Atlantic near the eastern boundary centred at $10^{\circ} \mathrm{S}, 8^{\circ} \mathrm{E}$, which is called the Angola Dome. The poleward extent of the OMZ in the eastern South Atlantic is similar to the extent in the North Atlantic. The southern limit of the $\mathrm{OMZ}$ is the Benguela Current transporting oxygen rich water north-westward into the tropical South Atlantic. A 'boundary', similar to the Cape Verde Frontal Zone in the North Atlantic, is the 
Angola-Benguela Frontal Zone (ABFZ) in the South Atlantic. The ABFZ is represented by a front between two different types of Central Water, the Eastern South Atlantic Central Water and the South Atlantic Central Water which stems in part from the Indian Ocean Central Water (Poole \& Tomczak, 1999).

Mercier et al. (2003) presented the oxygen distribution on two $R V$ L'Atalante sections located at about $9^{\circ} \mathrm{W}$ and $5^{\circ} \mathrm{E}$. Between $5^{\circ} \mathrm{S}$ and $20^{\circ} \mathrm{S}$ the oxygen minimum at $5^{\circ} \mathrm{E}$ is located at 300 to $500 \mathrm{~m}$ depth with concentrations less than $40 \mu \mathrm{mol} \mathrm{kg}{ }^{-1}$ (Mercier et al., 2003; their Fig. 4). At $9^{\circ} \mathrm{W}$ the oxygen minimum is larger with values of about $70 \mu \mathrm{mol} \mathrm{kg}{ }^{-1}$ between $4^{\circ} \mathrm{S}$ and $15^{\circ} \mathrm{S}$. In both sections the oxygen minimum is centred in the lower Central Water but reaches far into the AAIW layer. In measurements east of $8^{\circ} \mathrm{E}$ in April 1999 at a depth of $400 \mathrm{~m}$ the oxygen concentration between $8^{\circ} \mathrm{S}$ and $18^{\circ} \mathrm{S}$ was less than $43.5 \mu \mathrm{mol} \mathrm{kg}^{-1}\left(1 \mathrm{ml} \mathrm{l}^{-1}\right)$ (Mohrholtz, Schmidt, \& Lutjeharms, 2001).

The $R V L^{\prime}$ Atalante section at $5^{\circ} \mathrm{E}$ in March 1995 is reproduced in Fig. 3 for the region between $20^{\circ} \mathrm{S}$ and the equator. An interesting feature is the different depth of the oxygen minimum north and south of $12^{\circ} \mathrm{S}$. The oxygen minimum north of $12^{\circ} \mathrm{S}$ is similar to the North Atlantic located slightly above the Central Water/AAIW boundary. To the south of $12^{\circ} \mathrm{S}$ the oxygen minimum of less than $25 \mu \mathrm{mol} \mathrm{kg}^{-1}$ is spread over a wider depth range between 100 and $400 \mathrm{~m}$. This is the region of the Angola Gyre (Gordon \& Bosley, 1991), hence the Angola Gyre contains low-oxygen water trapped in its centre.

On the meridional section at $9^{\circ} \mathrm{W}$ Mercier et al. (2003; their Fig. 3) showed also a shallow $\mathrm{OMZ}$ at $11^{\circ} \mathrm{S}$ to $15^{\circ} \mathrm{S}$ compared to the depth of the $\mathrm{OMZ}$ north of $11^{\circ} \mathrm{S}$. According to Stramma \& England (1999) the subtropical gyre of the South Atlantic is located south of $15^{\circ} \mathrm{S}$ in the SACW layer in the central South Atlantic, and between the subtropical gyre and the eastward flowing South Equatorial Current at $9^{\circ}$ to $11^{\circ} \mathrm{S}$ there is a region of weak water renewal. The oxygen minimum at $9^{\circ} \mathrm{W}$ of about $70 \mu \mathrm{mol} \mathrm{kg}{ }^{-1}$ almost doubled compared to the minimum at $5^{\circ} \mathrm{E}$, hence this region at $9^{\circ} \mathrm{W}$ is still better supplied with oxygenated water than the water trapped in the Angola Gyre.

Chapman \& Shannon (1987) examined the seasonal large-scale distribution of the mean 
oxygen concentration at the oxygen minimum located between $\sigma_{\theta}=26.8$ and $27.0 \mathrm{~kg} \mathrm{~m}^{-3}$ and on the isopycnal $\sigma_{\theta}=26.9 \mathrm{~kg} \mathrm{~m}^{-3}$. The variations can be explained as being related to changes in the offshore wind field, which affect upwelling and hence primary production. The variance of the data is generally below 30\%, except within 2 degrees of the coast where upwelling and turbulence can cause aperiodic disruptions of the prevailing patterns. An obvious common feature is that there is a boundary separating the water low in oxygen to the north and east from the better-oxygenated water to the south-west, with the $87.0 \mu \mathrm{mol} \mathrm{kg}{ }^{-1}\left(2 \mathrm{ml} \mathrm{l}^{-1}\right)$ isoline at about $15^{\circ}$ to $18^{\circ} \mathrm{S}$ at $5^{\circ} \mathrm{W}$ and $20^{\circ}$ to $22^{\circ} \mathrm{S}$ at $10^{\circ} \mathrm{E}$.

The CFC-11 inventory (Willey at al., 2004) showed a somewhat lower inventory for the eastern South Atlantic than for the eastern North Atlantic which is in agreement with a less intensive ventilation from the outcrop.

\subsection{The OMZ in the Costa Rica Dome region}

The dynamics of the Costa Rica Dome $\left(9^{\circ} \mathrm{N}, 90^{\circ} \mathrm{W}\right)$ is slightly different from its cousins in the Atlantic as it is also forced by a coastal wind jet (Fiedler, 2002). Again the OMZ also covers the Central Water and Intermediate Water layers. A typical upper boundary for the Intermediate Water in the North Pacific is at about $\sigma_{\theta}=26.6 \mathrm{~kg} \mathrm{~m}^{-3}$ (e.g. $26.64 \mathrm{~kg} \mathrm{~m}^{-3}$ by Talley, 1997). Tomczak (1984b) investigated the density range $\sigma_{\theta}=25.2$ to $26.4 \mathrm{~kg} \mathrm{~m}^{-3}$ in the Pacific. He described for the North Pacific the Central Water varieties of Eastern North Pacific Central Water (ENPCW) and Western North Pacific Central Water (WNPCW). These water masses meet in the equatorial region to form Pacific Equatorial Water (PEW) which spreads eastward in a narrow band between the equator and $5^{\circ} \mathrm{S}$ as a contribution to the Equatorial Undercurrent (Tsuchiya, 1981). A front at 5 to $10^{\circ} \mathrm{N}$ separates PEW from ENPCW east of $170^{\circ} \mathrm{W}$. Certain density ranges are comparably well ventilated through the existence of Mode Waters which are embedded in the Central Water layer (Hanawa \& Talley, 2001; Suga, Aoki, Saito \& Hanawa, this issue).

For the Intermediate Water of the Pacific Ocean Reid (1965) stated that the oxygen minimum lies in the cyclonic gyre found between the NEC and the NECC. The waters 
of the California Current that reach a latitude of $20^{\circ} \mathrm{N}$ (on the thermosteric anomaly surface of $125 \mathrm{cl} /$ ton) have already lost a substantial part of their oxygen by lateral mixing with the countercurrent of the eastern boundary. Instead of flowing directly into the eastern tropical Pacific, they turn westward to feed the NEC. There is some enhancement of oxygen in the far west by lateral mixing with waters from the South Pacific that have crossed the equator north of New Guinea. As a result the NECC supplies water of relatively high oxygen towards the eastern basin. Values greater than $43.5 \mu \mathrm{mol} \mathrm{kg}{ }^{-1}\left(1 \mathrm{ml} \mathrm{l}^{-1}\right)$ are found as far east as $120^{\circ} \mathrm{W}$ (Reid, 1965). Wijffels, Toole, Bryden, Fine, Jenkins et al. (1996) described the water masses along $10^{\circ} \mathrm{N}$ and concluded that the Intermediate Water salinity minimum stems from the northern Pacific, where it is formed by contributions from the Sea of Okhotsk and the gyre boundary in the north-western Pacific (e.g., Talley, 1997). This water is flowing south on the eastern side of the North Pacific subtropical gyre and is called North Pacific Intermediate Water. However, even AAIW has been found along a section at $135^{\circ} \mathrm{W}$ northward of $6.5^{\circ} \mathrm{N}$ (Tsuchiya \& Talley, 1996).

In large scale parameter distributions on selected density surfaces of the Pacific Ocean Reid (1997) showed that the isopycnal $\sigma_{\theta}=26.8 \mathrm{~kg} \mathrm{~m}^{-3}$ lies at a depth of 400 to $500 \mathrm{~m}$ near the equator. It does not outcrop in the North Pacific and thus the oxygen there is much lower and the nutrients higher than in the South Pacific. According to Fig. $1 \mathrm{~b}$ the OMZ has its largest westward extension in the tropical North Pacific at around $10^{\circ} \mathrm{N}$. A zonal section centred almost completely in the middle of the OMZ was measured in April/May 1989 and is shown for the region east of $160^{\circ} \mathrm{W}$ in Fig. 4. Oxygen values of less than $50 \mu \mathrm{mol} \mathrm{kg}{ }^{-1}$ cover almost the entire section below about $100 \mathrm{~m}$ depth. Suboxic conditions (oxygen below $4.5 \mu \mathrm{mol} \mathrm{kg} \mathrm{kg}^{-1}$ ) are found east of $135^{\circ} \mathrm{W}$.

A meridional hydrographic section in March/April 1993 from $R V$ Knorr from the South Pacific along about $85^{\circ} \mathrm{W}$ (location see Fig. 1 a) to Central America shows a thick layer of dissolved oxygen below $10 \mu \mathrm{mol} \mathrm{kg}{ }^{-1}$ (Fig. 5; with the same gray scale as in Fig. 4). The darkest grey shading delineates values of less than $5 \mu \mathrm{mol} \mathrm{kg}{ }^{-1}$ found south of Central America and north of $5^{\circ} \mathrm{N}$ in a depth range between 300 to $900 \mathrm{~m}$ depth.

The large scale distribution of oxygen on a fixed depth surface (Fig. 1 a) might be 
misleading due to the significant depth variations of the isopycnals surfaces (e.g. Talley, Joyce and deSzoeke, 1991). The low oxygen values in the North Pacific at $400 \mathrm{~m}$ depth (Fig. 1 a) are located on much denser waters as the tropical oxygen minimum zone and there is no direct inflow of the low oxygen water of the North Pacific to the tropical OMZ as could be falsely concluded from Fig. 1a. The thickness of the layer with oxygen below $90 \mu \mathrm{mol} \mathrm{kg} \mathrm{k}^{-1}$ (Fig. 1 d) suggests that the equatorial oxygen minimum zone is a large pool which reaches from the $20^{\circ} \mathrm{N}$ to $15^{\circ} \mathrm{S}$ along the eastern Pacific with a maximum in thickness near the Costa Rica Dome. A rough comparison with CFC-11 inventory (Willey et al., 2004) shows low values for a similar region covering the Costa Rica Dome region and extending to the west. This is consistent with low ventilation and the lack of a direct outcrop pathway.

\subsection{The OMZ off Peru and Chile}

The eastern South Pacific shows no obvious signatures of a prominent dome when compared to the eastern North Pacific and Atlantic. However, independent of the presence of a thermal dome a well developed OMZ exists in the eastern South Pacific off Peru and Chile. Reid's (1965) maps of oxygen for the intermediate layers of the Pacific have considerably higher concentrations in the South Pacific than the North Pacific. He points out that in the South Pacific renewal of intermediate layers via direct air-sea exchange is possible, but not the case in the North Pacific. A typical lower boundary for the Central Water in the South Pacific is $\sigma_{\theta}=26.9 \mathrm{~kg} \mathrm{~m}^{-3}$ and associated with Subantarctic Mode Water (McCartney, 1977).

The OMZ of the South Pacific reaches also suboxic conditions with minimum values only slightly higher than in the North Pacific (Table 1). The lowest concentrations found at depths of a few hundred meters close to Peru. Warren (1995) found the oxygen consumption rate in the Peruvian upwelling system to be an order of magnitude greater than that in oligotrophic (low organic matter) waters offshore. However, the large areal extent of the $\mathrm{OMZ}$ is not just caused by the oxygen demand within Peruvian upwelling but also related to ocean circulation as will be shown below. 
The meridional section along $88^{\circ} \mathrm{W}$ (Tsuchiya \& Talley, 1998, Fig. 5) shows particularly low oxygen content between $3^{\circ} \mathrm{S}$ and $17^{\circ} \mathrm{S}$. The centre of the OMZ is located near $400 \mathrm{~m}$ depth north of $10^{\circ} \mathrm{S}$. Similar to the South Atlantic a double minimum occurs with a shallower minimum at a depth near $300 \mathrm{~m}$ south of $10^{\circ} \mathrm{S}$. The thickness of suboxic conditions of less than $4.5 \mu \mathrm{mol} \mathrm{kg}{ }^{-1}$ (white contour in Fig. 5) reaches $400 \mathrm{~m}$ in the South Pacific. Measured oxygen from bottle data shows the exsitance of oxygen values lower than $1.5 \mu \mathrm{mol} \mathrm{kg}-1$ in the eastern part of the tropical South Pacific. At about $18^{\circ} \mathrm{S}$ the southern low-oxygen domain is bound by a sharp increase in oxygen of more than $40 \mu \mathrm{mol} \mathrm{kg}{ }^{-1}\left(1 \mathrm{ml} \mathrm{l}^{-1}\right)$ within in $100 \mathrm{~km}$ (Tsuchiya \& Talley, 1998).

The South Pacific CFC-11 inventory (Willey et al., 2004) show very low ventilation centred at about $10^{\circ} \mathrm{S}$ and $90^{\circ} \mathrm{W}$ with values significantly lower than in the Atlantic. However, the South Pacific inventories south of $30^{\circ} \mathrm{S}$ are comparable to their Atlantic counterparts. For both basins this is consistent with an intense ventilation from the outcrop of this density range along the southern boundary of the subtropical gyre (Karstensen \& Quadfasel, 2002).

\section{Oxygen consumption and oxygen supply}

After the description of the OMZ's in the Atlantic and Pacific a more quantitative assessment of the large scale oxygen balance will be done. In a steady state ocean, the oxygen distribution at any given point below the euphotic zone is determined by a balance between oxygen supply through ocean transport $\left(\mathrm{O}_{2 \text {,transport }}\right)$ and oxygen consumption through biogeochemical processes $\left(\mathrm{O}_{2 \text {,consumption }}\right)$. Such a balance needs to exist over the $\mathrm{OMZ}$ volume and can be simply written as

$$
\partial \mathrm{O}_{2} / \partial \mathrm{t}=0=\mathrm{O}_{2, \text { consumption }}-\mathrm{O}_{2, \text { transport }}
$$

We will seek to evaluate these terms and check their consistency. Often the advection/diffusion equation of oxygen is analyzed in this context (e.g. Sverdrup, 1938; Wyrtki, 1962) leaving a number of open constrains. We follow here a much simpler 
approach concentrating on single numbers for supply and consumption as illustrated in Fig. 6. Note, in the following assessment we define three OMZ oxygen thresholds of $4.5 \mu \mathrm{mol} \mathrm{kg}{ }^{-1}$ (suboxic), $45 \mu \mathrm{mol} \mathrm{kg}{ }^{-1}$ and $90 \mu \mathrm{mol} \mathrm{kg}{ }^{-1}$.

\subsection{Oxygen consumption $\left(O_{2, \text { consumption }}\right)$}

As mentioned in chapter 2.2.3 oxygen consumption will be described in terms of the apparent oxygen utilization rate (aOUR) based on apparent oxygen utilization (AOU) and water ages (based on CFC-11 and ${ }^{14} \mathrm{C}$ ).

$$
\text { aOUR }=\text { AOU } /(\text { water age })
$$

The GLODAP data set provides AOU as well as CFC-age and CR-age and the aOUR can be easily calculated. However care should be taken when selecting AOU and water 'age' data because:

(a) the tracer age should be representative for the bulk of the water parcel under consideration. The ocean is in different states in respect to its equilibration with $\mathrm{CFC}$ and ${ }^{14} \mathrm{C}$. We concentrate here of $\mathrm{CFC}-11$ that was introduced into the atmosphere (and ocean) in significant amounts since the 1950s while its concentration in the atmosphere levelled out in the mid 1990s. Therefore CFC-11 water ages cover only a few decades which is however the typical ventilation time for most of the depth range which hosts the OMZ's. CFC ages in regions with low CFC-11 concentrations always need to be interpreted with caution as they may strongly affected through mixing with $\mathrm{CFC}-11$ free water and may be not longer representative for the bulk of the water parcel. The detection limit for CFC-11 is extremely low (typically $0.004 \pm 0.005 \mathrm{pmol} \mathrm{kg}^{-1}$ ) and even the admixture of a very small amount of CFC-11 bearing water can be detected. Consequently, if say the majority of a water parcel is composed by water which left the surface 200 years ago but it carries a small admixture of detectable CFC-11 the whole parcel is interpreted to be formed after the 1950's. Obviously such a CFC-age is not representative for the gros of the water parcel and should be excluded from the 
analysis.

${ }^{14} \mathrm{C}$ based $\mathrm{CR}$-ages cover a much longer time range and the ocean may have been once in equilibrium in respect to ${ }^{14} \mathrm{C}$. However, since the industrialization and the nuclear bomb testing in the 1950's the isotopic composition of the ocean has changes (so called 'Suess effect') (e.g. Sonnerup et al., 1999). Therefore CR-ages are more representative for the deeper ocean which is not much influenced by the Suess effect. We consider here CR-ages to be representative at the lower boundary of the thermocline depth range (1500 $\mathrm{m}$ in our case).

(b) the effect of along-isopycnal mixing on water ages and AOU should be small. Not only the mixing with CFC free water alters the aOUR. One dimensional pipeflow type along-isopycnal mixing can change the CFC-age of the water as a result of the non-linear time history of the CFCs (e.g. Karstensen \& Tomczak, 1998; Sonnerup, 2001; Mecking, Warner, Greene, Hautala, \& Sonnerup, 2004). To a first order an increase or decrease of the age through along-isopycnal mixing depend on the curvature of the time history. CFC ages derived from mid 1980s atmospheric equivalent are biased too young while younger ages are biased too old - however, considering typical diffusivity and using only CFC data with an atmospheric equivalent after 1960 results in an 5\% error on the $\mathrm{CFC}$ age compared to the advection time. For very diffusive systems, as the lower thermocline of the North Pacific, the CFC age error can be much higher and Mecking et al. (2004) report on 20 to 30 years 'biased too young' CFC ages. The selection criteria we apply to the data will not consider data in what we define as 'lower thermocline' of the North Pacific and we will assume a nominal uncertainty in CFC ages by double of what has been reported.

(c) only one biogeochemical cycling regime (remineralization or denitrification) should be considered. The way oxygen is involved in the biogeochemical processes during remineralization or during denitrification is different and thus represented by different aOUR. In our case we focus on respiration during remineralization of nutrients, which mainly determines the consumption in

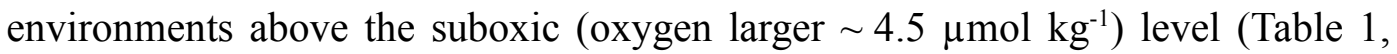
Fig. 7). As nitrite is released as a by-product during denitrification its appearance 
helps to identify water parcels affected by denitrification. However, not only the biogeochemical cycling within the suboxic environments where denitrification takes place but the admixture of water once affected by denitrification (Gruber \& Sarmiento, 1997) may alter the AOU. The change would be as such that AOU does virtually not change in suboxic environments (as no oxygen is available for consumption) while the CFC content may still increase. Hence the water parcels continues to get a different age when spreading in a suboxic environment while AOU remains the same. Typically the bulk of what composes a water parcel in the denitrification regions is rather old it may still have some CFC in it and thus a formation in the 1960s (low CFC-11 content) would be allocated to such a parcel while this age might be not representative for the bulk of the water composing the parcel. Such a combination of AOU and CFC age would give an apparently smaller than 'real' aOUR value. This is situation is particular evident for the Pacific (van Geen, Smethie, Horneman, \& Lee, 2006) which has a comparable large volume (Table 1) of water with denitrification signatures (Gruber \& Sarmiento, 1997). Again the selection criteria we apply below should exclude most of this data.

To meet the the three above mentioned requirements as close as possible the following, in part redundant, selection criteria have been used to select the appropriate GLODAP data for our aOUR analysis: (i) CFC-age identifies water formation before 1993 and after 1960. (ii) Nitrite levels are below $0.01 \mu \mathrm{mol} \mathrm{kg} \mathrm{kg}^{-1}$. (iii) Data is below euphotic zone (below 100m). (iv) Mixing with CFC-11 free water below $500 \mathrm{~m}$ is avoided. (iv) AOU $>30 \mu \mathrm{mol} \mathrm{kg}{ }^{-1}$ to ensure a certain integration time scale of the AOU.

Based on the individual aOUR estimates from the selected GLODAP data (Fig. 8) a non-linear minimization fit to a logarithmic function of the form

$$
\mathrm{aOUR}=\mathrm{c}_{1}+\mathrm{c}_{2} \cdot \exp (-\lambda \cdot \mathrm{z})
$$

was applied. It gave $c_{1}=-0.5, c_{2}=12, \lambda=0.0021$ for depth between $100 \mathrm{~m}$ and $1500 \mathrm{~m}$. 


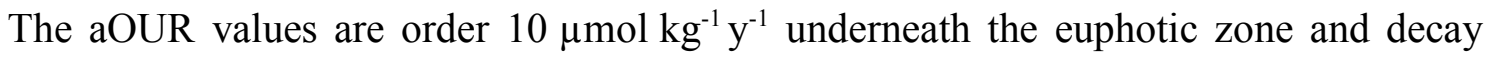
exponential to the CFC-ages based value of about $0.015 \mu \mathrm{mol} \mathrm{kg} \mathrm{kg}^{-1} \mathrm{y}^{-1}$ at $1500 \mathrm{~m}$ depth (Fig. 8). Although we first did the fit separating Atlantic and Pacific Ocean it turned out that their fit was rather similar and only one fit is given here but valid for both oceans (as shown for both ocean in Fig. 8). Mecking et al. (2006) gives aOUR estimates for the

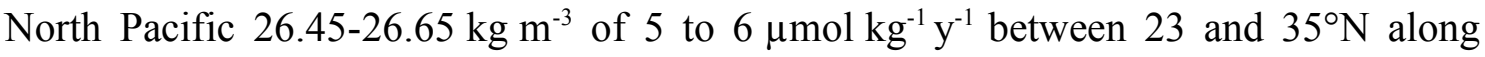
$152^{\circ} \mathrm{W}$ which agree with our estimates for this density range. However, our fit results in higher aOUR for the North Pacific compared to Feely et al. (2004). Two reasons have been identified: First, Feely et al. apply an age correction that essentially increases the CFC ages. Consequently the aOUR will decrease, as a longer time is needed to consume a certain amount of oxygen. Second, Feeley et al. consider all consumption processes to take place on the same time scale without distinguishing consumption through remineralization or denitrification. Again this would underestimate the aOUR as for denitrification the water age will increase although the AOU will be constant as virtually no oxygen is left for consumption. Note again even water outside the 'active' denitrification zone is potentially affected by denitrification through mixing. When deriving an oxygen age later we assume $20 \%$ error on the aOUR values.

It should be noted that there are other possibilities to derive an aOUR for example using sediment trap data and assuming a certain stoichiometry (e.g. Suess, 1980). However, there is a fundamental difference between sediment trap based aOUR and the aOUR derived here from water-ages: the sediment trap based aOUR is derived from the gradient in material caught in traps at different depth. Thus this aOUR is a measure of the vertical consumption rate. In contrast, the aOUR based on AOU and water ages integrates the oxygen modification (removal and production) along the spreading path of the water that is in the first order along isopycnal from the outcrop to a certain point in the ocean.

\subsection{Oxygen supply $\left(O_{2, \text { transport }}\right)$}

Our analysis of the oxygen supply is based on a so-called 'turn-over time' $\left(\tau_{0}\right)$, 
introduced by Bolin \& Rhode (1973). The $\tau_{0}$ is equal to the ratio of reservoir volume versus flux into this reservoir and can be interpreted as the average transit time of particles that leave the reservoir. In our case we define $\tau_{0}$ for isopycnal layers (left part of Fig. 6). Based on a similar conceptual model observations of transient tracer content (tritium, CFC) have been used to estimate ventilation rates $\left(S_{a n n}\right)$ considering the respective ocean volume (e.g. Sarmiento, 1983; Smethie \& Fine, 2001). Two important assumptions need to be made: (1) diapycnal fluxes (e.g. diffusion) are ignored. (2) Particle pathways are not directly considered (e.g. shadow zone, Luyten et al., 1983).

For our analysis the ventilating rates $\left(\mathrm{S}_{\mathrm{ann}}\right.$ in Fig. 6$)$ is based on an analysis of SODA model output (as explained in chapter 2.2). The ventilation rate at each grid point is converted into a ventilation flux when multiplied with the area associated with each grid point. As subduction for the main thermocline typically occurs in late winter and originates from the base of the mixed layer we consider the late winter mixed layer base density as our reference. We consider the $\mathrm{OMZ}$ core density range between 25.0 and $27.2 \mathrm{~kg} \mathrm{~m}^{-3}$ in density bins of $0.1 \mathrm{~kg} \mathrm{~m}^{-3}$ width using the equator as a separator between northern and southern hemisphere and the outcrop as the natural poleward limit.

For reference, and as it will be used in our simple ventilation model, the increase of volume with depth for the isopycnals is shown in Figure 9. The volumes in the Pacific (up to $50^{\circ} \mathrm{N}$ ) are order 3 times larger than in the Atlantic. The volume of the thermocline is largest in the South Pacific $\left(64 \cdot 10^{15} \mathrm{~m}^{3}\right)$, followed by the North Pacific $\left(41 \cdot 10^{15} \mathrm{~m}^{3}\right)$, the South Atlantic $\left(22 \cdot 10^{15} \mathrm{~m}^{3}\right)$, and finally the North Atlantic $\left(20 \cdot 10^{15} \mathrm{~m}^{3}\right)$. However, the differences in ocean basin volume do not translate directly into the volumes occupied by the OMZ's (Fig. 7, Table 1). Although it has only the second largest volume, the North Pacific has the largest pool of suboxic $(0.8 \%$ of the total volume) and OMZ waters, with about $20 \%\left(11 \cdot 10^{15} \mathrm{~m}^{3}\right)$ and $40 \%\left(21 \cdot 10^{15} \mathrm{~m}^{3}\right)$ occupied by water with oxygen content below $45 \mu \mathrm{mol} \mathrm{kg}{ }^{-1}$ and $90 \mu \mathrm{mol} \mathrm{kg}^{-1}$, respectively. For the South Pacific, which has the largest ocean volume, about 2\%o are occupied by anoxic waters, and 7\% and 13\% for OMZ waters below $45 \mu \mathrm{mol} \mathrm{kg}^{-1}$ and $90 \mu \mathrm{mol} \mathrm{kg}{ }^{-1}$, respectively. Occupying only about $1 / 3$ of the Pacific Ocean volume, the Atlantic Ocean is much more saturated in oxygen with no significant anoxic conditions as mentioned earlier. OMZ conditions below $45 \mu \mathrm{mol} \mathrm{kg}^{-1}$ occupy about $1 \%$ in the 
South Atlantic but no significant volume in the North Atlantic. The OMZ threshold of $90 \mu \mathrm{mol} \mathrm{kg}{ }^{-1}$ occupies about $5 \%$ and $7 \%$ in the North and South Atlantic thermocline volume, respectively. Using the Helly \& Levin threshold of $20 \mu \mathrm{mol} \mathrm{kg}^{-1}$ the North and South Atlantic have no OMZ volume (based on the WHP SAC data), while North Pacific and South Pacific would have a volume of $5 \cdot 10^{15} \mathrm{~m}^{3}$ and $1.8 \cdot 10^{15} \mathrm{~m}^{3}$, respectively.

The ventilation flux (Fig. 9, lower) does not follow the same exponential increase with density as the volume does (Fig. 9, upper). For each ocean there are certain density ranges with higher ventilation associated with Mode Water formation (Hanawa \& Talley, 2001). The North Pacific shows only very limited ventilation through subduction confirmed to densities less than $26.5 \mathrm{~kg} \mathrm{~m}^{-3}$ (in SODA). The South Pacific, which has the largest volume, has also the strongest ventilation rate. Less dense water is well ventilated (part of the Eastern Subtropical Mode Water, Hanawa \& Talley, 2001) but for densities between 26.0 and $26.6 \mathrm{~kg} \mathrm{~m}^{-3}$ only a more sluggish ventilation occurs. This density range coincides with the observed ranges of low oxygen conditions in the South Pacific. Ventilation increases again for the Subantarctic Mode water with densities centred at $26.9 \mathrm{~kg} \mathrm{~m}^{-3}$. The North and South Atlantic are relatively homogeneous in ventilation order 1 to $2 \mathrm{~Sv}$ for most density bins. There is a peak in ventilation centred at about $26.2 \mathrm{~kg} \mathrm{~m}^{-3}\left(18\right.$ to $\left.19^{\circ} \mathrm{C}\right)$ in the North Atlantic and associated with the formation of Subtropical Mode Water (Eighteen Degree Water). Although the density is about $0.2 \mathrm{~kg} \mathrm{~m}^{-3}$ lower compared to the 'classical' definition (Hanawa \& Talley, 2001) a recent warming has been reported (Kwon \& Riser, 2004) and may explain the difference in the 1992 to 2001 SODA ocean reanalysis product.

The turn-over time $\tau_{0}$ based on the volume (Fig. 9, upper) and ventilation flux (Fig. 9, lower) is shown in Figure 10. Note, the uncertainty in $\tau_{0}$ is based on an uncertainty in subduction rates that has been estimated to be on the order of $20 \%$ (Karstensen \& Quadfasel, 2002). The generally lower $\tau_{0}$ in the southern hemisphere oceans indicate a better ventilation of the southern hemisphere gyres. In the upper layers all oceans are well ventilated with with $\tau_{0}$ of less than a decade. Taking the equator as a separator $\tau_{0}$ rapidly increases to several decades and even up to centuries for the deeper North 
Atlantic. However, cross equatorial import of thermocline water from the south compensate for this lack in ventilation (compare Fig. 12, lower right). It has been reported before that the North Atlantic south of the Cape Verde Frontal Zone at about $16^{\circ} \mathrm{N}$ is predominately ventilated with water of South Atlantic origin (Sarmiento, 1983; Tomczak, 1984a). The South Atlantic is, in reference to it volume, best ventilated with rather short $\tau_{0}$. The North and South Pacific show overall a wider range of transit times For densities above $26.4 \mathrm{~kg} \mathrm{~m}^{-3}$ no ventilation occur in the North Pacific and $\tau_{0}$ is indefinite. For both oceans the long times are associated with the cores of the suboxic OMZ's (compare Tab. 1). Shorter $\tau_{0}$ are found for 26.8 and $26.9 \mathrm{~kg} \mathrm{~m}^{-3}$ and are associated with intense Sub-Antarctic Mode Water formation.

\subsection{Combining supply and consumption estimates: oxygen age and turn-over time}

Is there consistency between oxygen 'supply', in reference to a turn-over time $\tau_{0}$, and consumption, in reference to an aOUR? To perform a comparison we used the climatological AOU of the WHP-SAC climatology and the empirical fit between aOUR and depth (equ. 3) to calculate oxygen ages. For each data point one oxygen age is derived and it is assumed that it represent the first moment of the real age spectra of the source water ages that compose the water parcel. Within each isopycnal a distribution of 'oxygen ages' is obtained (Fig. 11) which has again a first moment or average oxygen age $\left(\tau_{\mathrm{a}}\right)$. The $\tau_{\mathrm{a}}$ can be compared with the turn-over time to check consistency.

To account for uncertainties in the oxygen ages we followed a Monte Carlo approach, adding normal distributed random noise of the order of $20 \%$ on the aOUR. However, the influence on the oxygen age distribution as well as on the average oxygen age was small. Note that the oxygen age can be much larger than CFC-ages as we used an aOUR that was derived by combining CFC-ages and CR-age.

We classify the oxygen age distribution into three 'typical' shapes (Fig. 11): (1) distributions with a rather exponential decay from young to old ages, as in the upper thermocline of Atlantic and South Pacific. As we are not excluding the mixed layer values in the outcrop region, a single peak of young water with exponential decay (shape 1) is associated with a rather isopycnal spreading of waters from the outcrop but 
without recirculation of water within the isopycnal and with a shrinking of the volume of that isopycnal range away from the outcrop. (2) Solitary peak distributions as for the North Pacific. A solitary single peak (shape 2), as in the North Pacific, is associated with a intensive recirculation of water. In the North Pacific the recirculation can be explained through the absence of an outcrop in the subtropical gyre for water denser $26.6 \mathrm{~kg} \mathrm{~m}^{-3}$. (3) Double or multiple peak oxygen age distributions, as for the Atlantic and South Pacific for water denser $\sim 26.4 \mathrm{~kg} \mathrm{~m}^{-3}$. Double peak oxygen age distributions (shape 3) are a mixture of advection from the outcrop and a recirculation of water within the isopycnal. Such distributions may appear if different modes of ventilation such as a Mode Water formation within a Central Water layer exist. Such a side-by-side existence of old and young waters within one isopycnal have been shown from observational data by Karstensen \& Tomczak (1998). In general these shapes are rather similar to what has been found by Haine \& Hall (2002) from an combined water mass and age distribution analysis and based on ideal age tracer experiments using an ocean model of the North Atlantic. However, note again that the age distributions by Haine \& Hall (2002) are real spectra of individual source water fractions and source water ages. Our oxygen age distributions are the distributions of the first moment of ages in the respective density interval.

Normalized by its maximum in each isopycnal the oxygen age distribution for each isopycnal is shown in Figure 12. The average oxygen age (first moment of the oxygen age distribution) as well as the turn-over time ( $\tau_{0}$; as in Fig. 10) are given for reference. The contour of the distribution for the North and South Atlantic (Fig. 12, right) are rather similar: oxygen ages for isopycnals less dense than $26.4 \mathrm{~kg} \mathrm{~m}^{-3}$ follow an exponential decrease (shape 1) indicating direct ventilation form a single outcrop source. For the denser waters a double peak structure in oxygen age distribution develops, one peak for very young waters while the more pronounced peak is for the older waters (consequently the average age $\tau_{\mathrm{a}}$ represents ages between the two peaks). This shape indicates two ventilation pathways: a recirculating part and a direct outcrop ventilation. The oxygen age of the recirculation peak increases with depth (density) and indicates the average recirculation time for the isopycnals (increasing from 20 to 50 years for both, the North and South Atlantic). The turn-over time and the average oxygen age are rather similar for the South Atlantic which indicate that the isopycnals 
are well ventilated. Again it should be emphasized that $\tau_{0}$ and $\tau_{\mathrm{a}}$ are based on different conceptual views of the ventilation and derived from independent data. For the North Atlantic upper thermocline $\tau_{0}$ and $\tau_{\mathrm{a}}$ are similar with shape 1 distribution. With the appearance of the double peak oxygen age distribution (shape 3 ) the turn-over time and average age deviate significantly. We interpret this deviation as consequence of the significant contribution of the South Atlantic on the ventilation of the North Atlantic thermocline south of $20^{\circ} \mathrm{N}$ (e.g. Sarmiento, 1983, Tomczak, 1984a). Indeed, taking the Atlantic as a whole (Fig. 12, lower right), no significant deviation between $\tau_{0}$ and $\tau_{\mathrm{a}}$ occurs indicating a well ventilated regime.

There are fundamental difference in the shape of the age distribution of the North and the South Pacific: The North Pacific has, virtually for the whole density range, a solitary peak age distribution (shape 2), while the South Pacific has shape 1 and shape 3 distribution and thus has similarities with the North and South Atlantic. The shape 1 distribution in the North Pacific is a clear indicator for a dominance of recirculation of water. This is not only true for the density range that has no direct outcrop (denser $26.6 \mathrm{~kg} \mathrm{~m}^{-3}$ ) but even for the less dense water (say denser $25.2 \mathrm{~kg} \mathrm{~m}^{-3}$ ). The average oxygen age increase with density to more that 120 years and being much longer than one could resolve e.g. using CFC ages alone. For the outcropping density range (up to $26.6 \mathrm{~kg} \mathrm{~m}^{-3}$ ) an increasing difference between $\tau_{0}$ and $\tau_{\mathrm{a}}$ indicates that ventilation of isopycnals is too weak and diapycnal supply is of increasing importance (not accounted for in the turn-over time approach). Largest difference between $\tau_{0}$ and $\tau_{\mathrm{a}}$ occur for the density range that hosts the suboxic OMZ (compare Tab. 1). For the South Pacific the structure is the most complex with up to three peaks in the distribution for some isopycnals. One reason for the complexity is in the ventilation pattern for the South Pacific which has been identified to be three-fold (Karstensen, 2004): a rather homogeneous ventilation of all isopycnals in the western Pacific, a preferred ventilation of denser water along the southern rim of the subtropical gyre, and a re-ventilation for water less dense than $25.4 \mathrm{~kg} \mathrm{~m}^{-3}$ in the eastern South Pacific. For both Pacific basins the difference between $\tau_{0}$ and $\tau_{\mathrm{a}}$ increases remarkably for the density ranges which hosts the individual OMZ ranges (compare Tab. 1) and still persist even taking the Pacific as a whole (Fig. 12, lower left). At least for the South Pacific, the water denser than the OMZ core $\left(>26.8 \mathrm{~kg} \mathrm{~m}^{-3}\right)$ shows again a rather good agreement between $\tau_{0}$ and $\tau_{\mathrm{a}}$ and 
indicating a sufficient ventilation of the lower density range associated with the intensive Mode Water formation.

\section{Atlantic-Pacific Comparison}

An interesting feature in the global ocean oxygen distribution is that the oxygen minima in the eastern Pacific reach suboxic conditions, while the oxygen minima in the eastern Atlantic are much more oxygenated. The Pacific OMZ's have not only much lower values but also cover larger areas/volumes than the eastern Atlantic (compare Table 1, Fig. 1). However, what is true for the OMZ's is also true for the overall volume of the thermoclines: the Pacific has a three times larger volume than the Atlantic. The renewal trough subduction does not keep up with the loss over the larger volumes. This somewhat awkward combination of large volume and limited ventilation generates a pool of water with very low oxygen concentrations. The partitioning of Atlantic and Pacific Ocean ventilation and volume by ocean basin (Tab. 2) exemplifies the situation again: owing $72 \%$ of the volume only half $(52 \%)$ of the flux ventilates the Pacific. This situation is even more unfortunate for the North Pacific which occupies about a quarter of two oceans thermocline volume (28\%) but experience only an eights (14\%) of their thermocline ventilation. In contrast, the South Atlantic appears 'over-ventilated' (15\% in volume but $29 \%$ in ventilation). However, as mentioned before South Atlantic subduction contributes significantly to North Atlantic ventilation.

The $\tau_{0}$ estimate ignores the complexity of horizontal flow field as this is a 'one box per isopycnal' budget. In contrast the individual oxygen ages $(\tau)$, as well as the average oxygen age $\left(\tau_{\mathrm{a}}\right)$, account indirectly for complexity of flow pattern and mixing through the shape of their distribution. The suboxic OMZ density range sticks out clearly in the turn-over time but not in the average ages. This suggests that the maintenance/formation of the suboxic OMZ is to a first order related to the outcrop ventilation and not to particle pathways or even spatial variability in biogeochemical cycling. This finding has interesting consequences when discussing the variability of intensity and extend of OMZ's. 
Nevertheless, the geographic location of the OMZ's are tightly related to circulation pattern (Luyten et al., 1983; Warren, 1995). The OMZ's are located in the 'shadow zones' of the subtropical gyres which are a consequence of basic principles of the thermocline ventilation (Luyten et al., 1983). Essentially there is no meridional flow from the subtropics to the tropics and the transport is limited to a complicated system of zonal current and countercurrent of the equatorial current system. At a first glance the OMZ location is rather similar in the Pacific and Atlantic, however a number of differences exists: In the North Pacific the westward flowing North Equatorial Current is eastward near $5^{\circ} \mathrm{N}$ in the North Equatorial Counter Current, while in the South Pacific the South Equatorial Current enters a complicated current system in the western Pacific and some water returns eastward in the South Subsurface Counter Current at 3 to $5^{\circ} \mathrm{S}$ (Schott, McCreary \& Johnson, 2004; their Plate 2). In the North Atlantic the North Equatorial Current carries subtropical water to the western Atlantic. The North Equatorial Counter Current at about $5^{\circ} \mathrm{N}$ carries water westward, however this water originates mainly from the South Atlantic and is an important contributor to the North Atlantic thermocline ventilation. In the South Atlantic the South Equatorial Current feeds the complicated tropical current system and westward flow near $5^{\circ} \mathrm{S}$ is within the South Equatorial Undercurrent (Schott et al., 2004; their plate 3). As an example for the eastward supply of oxygen in the zonal equatorial currents the measured ADCP velocities are overlain on the oxygen distribution of a section at $28^{\circ} \mathrm{W}$ between $11.6^{\circ} \mathrm{S}$ and $2.5^{\circ} \mathrm{S}$ in May 2003 (Fig. 13 a). Although the velocity distribution is only an instant snapshot while the hydrographic parameter distribution represents the integrated longertime flow field, the eastward currents at 150 to $600 \mathrm{~m}$ depth are related to higher oxygen values, while the westward flow is connected to lower oxygen values (darker shading in Fig. 13 a). The increased oxygen values are especially true for the eastward currents with more than $10 \mathrm{~cm} \mathrm{~s}^{-1}$, the SEUC at $4^{\circ} \mathrm{S}$ to $5.5^{\circ} \mathrm{S}$ and the current band centred at $7.3^{\circ} \mathrm{S}$. The connection between the oxygen distribution and the zonal flow is particular evident looking on their averages in the depth range 200 to $500 \mathrm{~m}$ (Fig. $13 \mathrm{~b}$ ). The oxygen supply to the OMZ's is mainly from the west with near-equatorial currents. These current bands have to travel much longer distances in the Pacific and they contribute less oxygen to the oxygen minimum zones. 
Most obvious from the hydrographic sections is the fact that vertical extent of the layers with low oxygen is much greater in the Pacific than in the Atlantic (Tab. 1). On the zonal section at $10^{\circ} \mathrm{N}$ in the Pacific (Fig. 4) the $10 \mu \mathrm{mol} \mathrm{kg} \mathrm{kg}^{-1}$ contour below the OMZ reaches down 800 to 900 dbar and to 700 dbar in the South Pacific (Fig. 5) while in the Atlantic the 10 times larger $100 \mu \mathrm{mol} \mathrm{kg}{ }^{-1}$ contour below the OMZ's reach only to 700 to 800 dbar (Fig. 2 and 3).

\section{Conclusions}

As oxygen is a key parameter for ocean biogeochemical cycling and thus of importance to fully understand the oceans role in the climate system. In particular regions of low dissolved oxygen concentration, the OMZ's, have a strongly nonlinear effect on nutrient cycling and therefore are of increasing interest. Based on advection/diffusion equations Sverdrup (1938) and Wyrtki (1962) already concluded that the oxygen minimum layer is caused by the biogeochemical oxygen consumption and that their locations are determined by circulation. However, they considered more the general vertical distribution than the horizontal.

The analysis presented here is based on the joint analysis of simple models for oxygen consumption and oxygen supply: oxygen consumption was approximated via an apparent oxygen utilization rate (aOUR) derived by combining AOU and $\mathrm{CFC}-11 /{ }^{14} \mathrm{C}$ based water ages from the GLODAP climatology. Through a number of constrains on the data we derived the aOUR only in regions where consumption was linked to remineralization rather than denitrification and the effect of mixing on the 'age' was

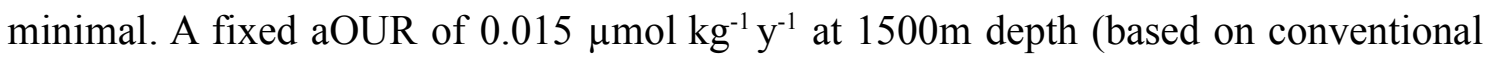
radiocarbon ages) was assumed. The regional non-linear fits to the aOUR in the Atlantic and Pacific were marginally different and a single global aOUR relationship with depth was derived. Oxygen supply was quantified considering the water mass formation rate in the outcrop areas $\left(25.0\right.$ to $\left.27.2 \mathrm{~kg} \mathrm{~m}^{-3}\right)$ normalized by the volume of the isopycnals (in $0.1 \mathrm{~kg} \mathrm{~m}^{-3}$ density bins). This ratio has the unit of time and is called the turn-over time $\left(\tau_{0}\right)$ by Bolin \& Rhode (1973).

The consistency between oxygen consumption and oxygen supply was analysed 
converting the consumption into an oxygen age. These calculations based on climatological AOU fields and an empirically derive aOUR fit. For each isopycnal a distribution of oxygen ages was found and an average oxygen age $\left(\tau_{\mathrm{a}}\right)$ could be compared to the turn-over time $\tau_{0}$. The general shape of $\tau_{\mathrm{a}}$ and $\tau_{0}$ revealed a logarithmic increase in ages with depth, as expected. However, the density range that hosts the suboxic $\left(<4.5 \mu \mathrm{mol} \mathrm{kg} \mathrm{kg}^{-1}\right)$ OMZ sticks out in the $\tau_{\mathrm{a}}$ approach with large ages. This suggests that the existence of suboxic OMZ's are mainly a results of sluggish ventilation over the outcrop rather than regionally increased high consumption rates. A significant deviation in turn-over time and average age in the North Atlantic could be attributed to the known ventilation of the North Atlantic thermocline from the South Atlantic (e.g. Sarmiento, 1983) and combining both oceans reveals no significant deviation between $\tau_{\mathrm{a}}$ and $\tau_{0}$. This suggest that the cross equatorial exchange in the Atlantic is of importance to prevent a suboxic OMZ in the North Atlantic.

Pathways of ocean transport determine the geographical location of the $\mathrm{OMZ}$ in the eastern tropical oceans in regions also know as the 'shadow zones' within the framework of thermocline ventilation (Luyten et al., 1983). For example higher oxygen in the North Atlantic OMZ seems to be due to inflow of oxygen rich water from the west in the NEUC, the NECC at 5 to $10^{\circ} \mathrm{N}$ and the NICC. The corresponding current bands in the Pacific have to travel much longer distances and should contribute less oxygen to the oxygen minimum zones. As the OMZ's show minimum oxygen values near the domes located in the eastern tropical Atlantic and eastern tropical North Pacific their presence has been argued to be responsible for OMZ generation at those locations. However, as the domes are manifested in the upper ocean hydrography only and as the eastern South Pacific, where no dome is situated, has a pronounced oxygen minimum the domes can't be responsible for the OMZ. The thickness of the layer with oxygen $<90 \mu \mathrm{mol} \mathrm{kg} \mathrm{kg}^{-1}$ suggest that the equatorial oxygen minimum zone is a rather large pool that reaches over the equator from the $20^{\circ} \mathrm{N}$ to $15^{\circ} \mathrm{S}$ along the eastern Pacific. It has the Costa Rica Dome, which indicates longest ventilation times in its centre as can be seen from CFC-11 inventories (Willey et al., 2004).

One reason for the different pattern in the oxygen distribution of the Pacific and Atlantic seems to be the different oxygen content in the eastward flowing equatorial 
currents. In the Atlantic, the water supply is from the well ventilated southern hemisphere. In the Pacific the equatorial circulation is fed by both the northern and southern hemisphere, while the southern hemisphere contributes about $60 \%$ (Rodgers, Blanke, Madec, Aumont, Ciais et al., 2003). Densities $>26.4 \mathrm{~kg} \mathrm{~m}^{-3}$ have only very localized outcrop in the subpolar gyre leading to much lower oxygen levels in the North Pacific in general and in the water masses which renew the OMZ's by the zonal equatorial currents. This supply of low oxygen water in the Pacific leads to a thicker OMZ in the Pacific. Taking the Pacific as a whole indicates that the current outcrop ventilation is still to weak for sufficient oxygen supply in the suboxic OMZ density range.

Taking OMZ threshold water with oxygen content below $4.5 \mu \mathrm{mol} \mathrm{kg}{ }^{-1}$ (suboxic), $45 \mu \mathrm{mol} \mathrm{kg}{ }^{-1}$ and $90 \mu \mathrm{mol} \mathrm{kg}{ }^{-1}$ one can see certain similarities between oxygen isoline and the location of upwelling regions (Fig. 14 a). The reason is apparently two fold and based on peculiarities of ocean biogeochemical cycling and ocean physics. High productivity in the surface layer through upwelling of nutrient rich water may require a rather large amount of oxygen in the vigorous biogeochemical cycling processes. This is what can be seen just at the upper layer of the OMZ regions. Following the ventilation concept by Luyten et al., (1983) upwelling causes vortex stretching at the mixed layer base and considering the conservation of potential vorticity at the base of the mixed layer the vortices are forced to propagate poleward along the eastern boundary which is against the large scale flow as a consequence of the large scale wind field. As a consequence the flow in the $\mathrm{OMZ}$ regions at the eastern boundaries is predominately zonal (and sluggish) (Fig. 14 b) and renewal of water masses diminished. The ultimate ventilation happens far away from the $\mathrm{OMZ}$ regions at the outcrop of the isopycnals.

The pattern of circulation in the $\mathrm{OMZ}$ core density range (Fig. $14 \mathrm{~b}$ ) of the North Pacific and North Atlantic have both a 'textbook' subtropical gyre circulation. Note, the flow trajectories represent a 10-year mean of the SODA horizontal velocity field. The most obvious difference between Pacific and Atlantic is the existence of a number of circulation cells equatorwards of $20^{\circ} \mathrm{N} / \mathrm{S}$ in the Pacific. They suggest intensive recirculation of waters and a barrier effect for the ventilation of the eastern boundary 
regions. Taking the long term mean of ocean chlorophyll data as determined from SeaWiFS (McClain, Feldman, \& Hooker, 2004) as an indicator for productivity and consequently for water column integrated activity of consumption one identifies that the productivity does not reach as far from the coast as it would be needed to explain the OMZ (Fig. 14 c). This highlights the role of ocean ventilation for the generation of an $\mathrm{OMZ}$.

However, more detailed studies on the exchanges between biogeochemical driven local upwelling regimes and the communication with the open ocean are needed. In respect to understand long term variability of the intensity and extend of OMZ's in the world ocean a change in the ventilation pattern, in particular the ventilation intensity (subduction) at the outcrop is one likely explanation. Both the anticipated change in thermocline ventilation levels as well as the uncertain response of the biogeochemical ecosystem to global warming warrant further study of the worlds oxygen minimum zones and their future evolution.

\section{Acknowledgments}

Stimulating comments by three anonymous reviewers are acknowledged. We are grateful to $H$. Bange for helpful comments, Xianhe Cao and Benjamin Giese for providing the SODA data (see also http://www.atmos.umd.edu/ ocean/), and J. Campell and J. Werdell for help with the SeaWiFS ocean color data. Financial support was received through the Deutsche Bundesministerium für Bildung und Forschung (BMBF) as part of the German CLIVAR project (03F0377B) 'Mechanism of tropicalsubtropical interactions in the Atlantic'. The hydrographic sections were made available through the CLIVAR and Carbon Hydrographic Data Office, La Jolla, CA, USA. 


\section{References}

Arhan, M., Mercier, H., Bourles, B., \& Gouriou, Y., (1998). Hydrographic sections across the Atlantic at $7^{\circ} 30 \mathrm{~N}$ and $4^{\circ} 30 \mathrm{~S}$. Deep-Sea Research I, 45, 829-872.

Bange, H.W., Naqvi, S.W., \& Codispoti, L.A., (2005). The nitrogen cycle in the Arabian Sea. Progress in Oceanography, 65, 145-158.

Bolin, B., \& Rhode, H., (1973). A note on the concepts of age distribution and transit time in natural reservoirs. Tellus, 25, 58-62.

Bopp, L., LeQuéré, C., Heimann, M., Manning, A.C., \& Monfray, P., (2002). Climateinduced oceanic oxygen fluxes: Implications for the contemporary carbon budget. Global Biogeochemical Cycles, 16, doi:10.10292001GB001445.

Carton, J. A., Chepurin, G., \& Giese, B. S., (2000). A simple ocean data assimilation analysis of the global upper ocean 1950-1995. Part I: Method. Journal of Physical Oceanography, 30, 294-309.

Carton, J. A., \& Giese, B. S. (submitted). SODA: A Reanalysis of ocean climate using SODA. Monthly Weather Review.

Chapman, P., \& Shannon, L.V., (1987). Seasonality in the oxygen minimum layers at the extremities of the Benguela system. South African Journal of Marine Sciences, 5, $85-94$.

Emerson, S., Mecking, S., \& Abell, J., (2001). The biological pump in the subtropical North Pacific Ocean: Nutrient sources, Redfield ratios, and recent changes. Global Biogeochemical Cycles, 15, 535-554.

Feely, R. A., Sabine, C.L., Schlitzer, R., Bullister, J. L., Mecking, S., \& Greeley, D., (2004). Oxygen Utilization and Organic Carbon Remineralization in the Upper Water Column of the Pacific Ocean. Journal of Oceanography, 60 (1), 45-52. 
Fiedler, P. C., (2002). The annual cycle and biological effects of the Costa Rica Dome. Deep Sea Research I, 49, 321-338.

Garcia, H.E., Boyer, T.P., Levitus, S., Locarnini, R.A., \& Antonov, J., (2005). On the variability of dissolved oxygen and apparent oxygen utilization content for the upper world ocean: 1955 to 1998. Geophysical Research Letters, 32, L09604, doi:1029/2004GL022286.

Gordon, A.L., \& Bosley, K.T., (1991). Cyclonic gyre in the tropical South Atlantic. Deep-Sea Research, 38 (Supl. 1), S323-S343.

Gouretski, V., \& Jahnke, K., (1998). A new world ocean climatology. WHP Special Analysis Centre. Technical Report No.3, Hamburg, Germany.

Gruber, N., \& Sarmiento, J.L., (1997). Global patterns of marine nitrogen fixation and denitrification. Global Biogeochemical Cycles, 11(2), 235-266.

Haine, T.W.N., \& Hall, T.M., (2002). A generalized transport theory: Water-mass composition and age. Journal of Physical Oceanography, 32, 1932-1946.

Hanawa, K., \& Talley, L.D., (2001). Mode Waters. In: Siedler, G., Church, J., \& Gould, J. (Ed.), Ocean Circulation and Climate, Observing and Modelling the Global Ocean. Academic Press, London, 373-386.

Helly, J., \& Levin, L., (2004). Global Distribution of Naturally Occurring Marine Hypoxia on Continental Margins. Deep-Sea Research I, 51: 1159-1168

Howell, E. A., Doney, S. C., Fine, R. A., \& Olson, D. B., (1997). Geochemical estimates of denitrification in the Arabian Sea and the Bay of Bengal during WOCE. Geophysical Research Letters, 24, 2549-2552. 
Jenkins, W. J., (1987). $3 \mathrm{H}$ and $3 \mathrm{He}$ in the beta triangle: Observations of gyre ventilation and oxygen utilization rates. Journal of Physical Oceanography, 17, 763-783.

Karstensen, J., (2004). Formation of the South Pacific Shallow Salinity Minimum: A Southern Ocean Pathway to the Tropical Pacific. Journal of Physical Oceanography, $34,2398-2412$.

Karstensen, J., \& Tomczak, M., (1998). Age determination of mixed water masses using CFC and oxygen data. Journal of Geophysical Research, 103(C9), 18599-18610.

Karstensen, J., \& Quadfasel, D., (2002). Formation of Southern Hemisphere Thermocline waters: Water mass Conversion and Subduction. Journal of Physical Oceanography, 32, 3020-3038.

Keeling, R.F., \& Garcia, H., (2002). The change in oceanic $\mathrm{O}_{2}$ inventory associated with recent global warming. Proceedings of the National Academy of Sciences of the United States of America, 99, 7848-7853.

Khatiwala, S., Visbeck, M., \& Schlosser, P., (2001). Age tracers in an ocean GCM. Deep Sea Research I, 48, 1423-1441.

Klein, B., Molinari, R.L., Müller, T.J., \& Siedler, G., (1995). A transatlantic section at 14.5N: Meridional volume and heat fluxes. Journal of Marine Research, 53, 929-957.

Kwon, Y., \& Riser, S. C., (2004). North Atlantic Subtropical Mode Water: A history of ocean-atmosphere interaction 1961-2000. Geophysical Research Letters, 31, L19307, doi:10.1029/2004GL021116.

Luyten, J.R., Pedlosky, J., \& Stommel, H., (1983). The ventilated thermocline. Journal of Physical Oceanography, 13, 292-309. 
Marshall, J.C., Nurser, A.J.G., \& Williams, R. G., (1993). Inferring the subduction rate and period over the North Atlantic. Journal of Physical Oceanography, 23,1315-1329.

Mataer, R.J., \& Hirst, (2003). Long-term changes in dissolved oxygen concentrations in the ocean caused by protracted global warming. Global Biogeochemical Cycles, 17(4), 1125, doi:10.1029/2002GB001997.

Mazeika, P.A., (1968). Thermal domes in the eastern tropical Atlantic Ocean. Limnology and Oceanography, 12, 537-539.

McCartney, M.S., (1977). Subantarctic Mode Water. In M. Angel, A voyage of discovery, Pergamon Press, Oxford, U.K., Vol. 24 (Suppl.), 103-119.

McClain, C.R., Feldman, G.C., \& Hooker, S.B., (2004). An overview of the SeaWiFS project and strategies for producing a climate research quality global ocean bio-optical time series. Deep Sea Research II, 51, 5-42.

Mecking, S., Warner, M. J., Greene, C., Hautala, S. L., \& Sonnerup, R.E., (2004). The influence of mixing on CFC concentrations and CFC-derived age distributions in the North Pacific thermocline, Journal of Geophysical Research, 109 (C07014), doi: 10.1029/2003JC001988

Mecking, S., Warner, M. J., \& Bullister, J. L., (2006). Temporal changes in pCFC-12 ages and AOU along two hydrographic sections in the eastern subtropical North Pacific. Deep-Sea Research I, 53, 169-187, 2006.

Meissner, K. J., Galbraith, E. D., \& Völker, C., (2005). Denitrification under glacial and interglacial conditions: A physical approach. Paleoceanography, 20, PA3001, doi:10.1029/2004PA001083. 
Mercier, H., Arhan, M., \& Lutjeharms, J.R.E., (2003). Upper-layer circulation in the eastern Equatorial and South Atlantic Ocean in January-March 1995. Deep-Sea Research, 50, 863-887.

Mohrholtz, V., Schmidt, M., \& Lutjeharms, J.R.E., (2001). The hydrography and dynamics of the Angola-Benguela Frontal Zone and environment in April 1999. South African Journal of Science, 97, 199-208.

Morrison, J.M., Codispoti, L.A., Smith, S.L., Wishner, K., Flagg, C., Gardner, W.D., Gaurin, S., Naqvi, S.W.A., Manghnani, V., Prosperie, L., \& Gundersen, J.S., (1999). The oxygen minimum zone in the Arabian Sea during 1995. Deep Sea Research II, 46, 1903-1931.

Murray, J.W., Stewart, K., Kassakian, S., Krynytzky, M., \& DiJulio, D., (2005). Oxic, Suboxic and Anoxic Conditions in the Black Sea. In: A. Gilbert, V. Yanko-Hombach and N. Panin, eds) Climate Change and Coastline Migration as Factors in Human Adaptation to the Circum-Pontic Region: From Past to Forecast. Kluwer Pub.

Poole, R., \& Tomczak, M., (1999). Optimum multiparameter analysis of the water mass structure in the Atlantic Ocean thermocline. Deep-Sea Research I, 46, 1895-1921.

Quadfasel, D.R., \& Schott, F., (1982). Water mass distributions at intermediate layers off the Somali coast during the onset of the southwest monsoon, 1979. Journal of Physical Oceanography, 12, 1358-1372.

Reid, J.L. Jr., (1965). Intermediate waters of the Pacific Ocean. Johns Hopkins Oceanographic Studies, 2, pp. 85.

Reid, J.L., (1997). On the total geostrophic circulation of the Pacific Ocean: flow pattern, tracers, and transports. Progress in Oceanography, 39, 263-352.

Rodgers, K.B., Blanke, B., Madec, G., Aumont, O.,P. Ciais, P., \& Dutay, J.-C., (2003). Extratropical sources of Equatorial Pacific upwelling in an OGCM. Geophysical Research Letters., 30(2), 1084, doi:10.1029/2002GL016003. 
Sabine, C. L., Key, R. M., Kozyr, A., Feely, R.A., Wanninkhof, R., Millero, F. J. , Peng, T.-H., Bullister, J. L., \& Lee, K. (2005). Global Ocean Data Analysis Project: Results and Data. ORNL/CDIAC-145, NDP-083. Carbon Dioxide Information Analysis centre, Oak Ridge National Laboratory, U.S. Department of Energy, Oak Ridge, Tennessee, $110 \mathrm{pp}$.

Sarmiento, J. L. (1983). A tritium box model of the North Atlantic thermocline. Journal of Physical Oceanography, 13, 1269-1274.

Schott, F.A., McCreary, Jr., J.P., \& Johnson, G.C., (2004). Shallow overturning circulations of the tropical-subtropical oceans. In. Wang, C., Xie, S.-P., \& Carton, J.A. (Ed.), Earth Climate: The Ocean Atmosphere Interaction. AGU Washington D.C., 261304.

Siedler, G., Zangenberg, N., Onken, R., \& Morliere, A., (1992). Seasonal changes in the tropical Atlantic circulation: Observations and simulations of the Guinea Dome. Journal of Geophysical Research, 97, 703-715.

Smethie Jr., W.M., \& Fine, R.A., (2001). Rates of North Atlantic Deep Water formation calculated from chlorofluorocarbon inventories. Deep-Sea Research, 48: 189-215.

Sonnerup, R.E., Quay, P.D., \& Bullister, J.L., (1999). Thermocline ventilation and oxygen utilization rates in the subtropical north Pacific based on CFC and $14 \mathrm{C}$ distributions during WOCE. Deep-Sea Research, I, 46, 777-805.

Sonnerup, R.E., (2001). On the relations among CFC derived water mass ages. Geophysical Research Letters, 28, 1739-1742.

Stramma, L., \& England, M., (1999). On the water masses and mean circulation of the South Atlantic Ocean. Journal of Geophysical Research, 104, 20,863-20,883. 
Stramma, L., Fischer, J., Brandt, P., \& Schott, F., (2003). Circulation, variability and near-equatorial meridional flow in the central tropical Atlantic. In: Goni, G.J., Malanotte-Rizzoli, P., (Ed.), Interhemispheric Water Exchange in the Atlantic Ocean. Elsevier Oceanographic Series 68, 1-22.

Stramma, L., Hüttl, S., \& Schafstall, J., (2005). Water masses and currents in the upper tropical Northeast Atlantic off northwest Africa. Journal of Geophysical Research, 110, C12006, doi:10.1029/2005JC002939.

Stramma, L., \& Schott, F., (1999). The mean flow field of the tropical Atlantic Ocean. Deep Sea Research, II, 46, 279-303.

Suess, E., (1980). Particulate organic carbon flux in the ocean - surface productivity and oxygen utilization. Nature, 288, 260 - 263, doi:10.1038/288260a0

Suga, T., Aoki, Y., Saito, H., \& Hanawa, K., (accepted). Ventilation of the North Pacific subtropical pycnocline and Mode Water formation. Progress in Oceanography, This issue.

Sverdrup, H.U., (1938). On the explanation of oxygen minima and maxima in the oceans. Journal du Conseil International pour l'Exploration de Mer, 13, 163-172.

Talley, L.D., (1997). North Pacific Intermediate Water transports in mixed water regions. Journal of Physical Oceanography, 27, 1795-1803.

Talley, L.D., Joyce, T.M., \& deSzoeke, R.A., (1991). Transpacific sections at $47^{\circ} \mathrm{N}$ and $152^{\circ} \mathrm{W}$ : distribution of properties. Deep Sea Research, 38, Suppl. 1, S63-S82.

Tomczak, M., (1999). Some historical, theoretical and applied aspects of quantitative water mass analysis. Journal of Marine Research, 57,275-303, 1999.

Tomczak, M. Jr., (1984a). Ausbreitung und Vermischung der Zentralwassermassen in den Tropengebieten der Ozeane. 1: Atlantischer Ozean. Oceanologica Acta, 7, 145-158. 
Tomczak, M. Jr., (1984b). Ausbreitung und Vermischung der Zentralwassermassen in den Tropengebieten der Ozeane. 1: Indischer und Pazifischer Ozean. Oceanologica Acta, 7, 271-288.

Tomczak, M., \& Godfrey, J.S., (1994). Regional Oceanography: An introduction. 422 pp, Elsevier, Oxford.

Tsuchiya, M., (1981). The origin of the Pacific equatorial $13^{\circ} \mathrm{C}$ Water. Journal of Physical Oceanography, 11, 794-812.

Tsuchiya, M., \& Talley, L.D., (1996). Water property distributions along an eastern Pacific hydrographic section at $135^{\circ} \mathrm{W}$. Journal of Marine Research, 54, 541-564.

Tsuchiya, M., \& Talley, L.D., (1998). A Pacific hydrographic section at $88^{\circ} \mathrm{W}$ : Waterproperty distribution. Journal of Geophysical Research, 103, 12,899-12,918.

UNESCO (1986). Progress on Oceanographic tables and standards 1983-1986: Work and recommendations of UNESCO/SCOR/ICES/IAPSO Joint Panel. UNESCO Technical Papers in Marine Science, No. 50, 59 pp.

van Geen, A., W. M. Smethie Jr., A. Horneman, and H. Lee (2006), Sensitivity of the North Pacific oxygen minimum zone to changes in ocean circulation: A simple model calibrated by chlorofluorocarbons, Journal of Geophysical Research, 111, C10004, doi:10.1029/2005JC003192.

Walker, S. J., Weiss, R. F., \& Salameh, P. K., (2000). Reconstructed histories of the annual mean atmospheric mole fractions for the halocarbons CFC-11, CFC-12, CFC113 and carbon tetrachloride. Journal of Geophysical Research, 105 (C6), 1428514296.

Wallace, D.W.R., \& Bange, H.W., (2004). Introduction to special section: Results of the Meteor 55: Tropical SOLAS experiment. Geophysical Research Letters, 31, L23S01, 
doi:10.1029/2004GL02014.

Warren, B. A., (1995). Context of the suboxic layer in the Arabian Sea. In D. Lal, Biogeochemistry of the Arabian Sea: Present information and gaps, (pp. 203-216). Indian Academy of Sciences 103.

Warner, M. J., \& Weiss, R. F., (1985). Solubilities of chlorofluorocarbons 11 and 12 in water and seawater. Deep-Sea Research, 32, 1485-1497.

Weiss, R. F., (1970). The solubility of nitrogen, oxygen and argon in water and seawater. Deep-Sea Research, 17, 721-735.

Willey, D.A., Fine, R.A., Sonnerup, R.E., Bullister, J.L., Smethie Jr., W.M., \& Warner, M.J., (2004). Global oceanic chlorofluorocarbon inventory, Geophysical Research Letters, 31, L01303, doi:10.1029/2003GL018816.

Wijffels, S.E., Toole; J.M., Bryden, H.L., Fine, R.A., Jenkins, W.J., \& Bullister, J.L., (1996). The water masses and circulation at $10^{\circ} \mathrm{N}$ in the Pacific. Deep Sea Research I, $43,501-544$.

Wyrtki, K., (1962). The oxygen minima in relation to ocean circulation. Deep Sea Research, 9, 11-23.

You, Y., \& Tomczak, M., (1993). Thermocline circulation and ventilation in the Indian Ocean derived from water mass analysis. Deep-Sea Research, 40, 13-56. 


\section{Figure captions}

Fig. 1: Distribution of a) annual mean dissolved oxygen $\left(\mu \mathrm{mol} \mathrm{kg} \mathrm{kg}^{-1}\right)$ at $400 \mathrm{~m}$ depth using a contour interval of $50 \mu \mathrm{mol} \mathrm{kg} \mathrm{kg}^{-1}$ based on WHP-SAC (Gouretski \& Jahnke, 1998) data. The centre locations of the thermocline domes are marked by white crosses, the oxygen sections shown in the following figures are indicated as white lines, $b$ ) oxygen at the oxygen minimum considering the upper $1400 \mathrm{~m}$ of the water column, c) depth of the oxygen minimum, and d) thickness of the layer with $\mathrm{O}_{2}<90 \mu \mathrm{mol} \mathrm{kg}^{-1}$.

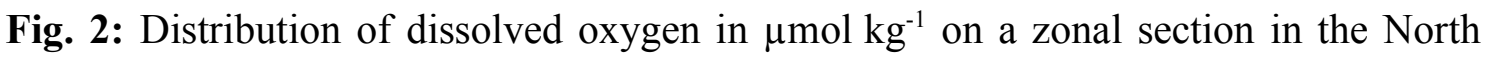
Atlantic along about $7^{\circ} 30^{\prime} \mathrm{N}$ east of $32^{\circ} \mathrm{W}$ in February/March 1993 from $R V L^{\prime}$ 'Atalante with a contour interval of $10 \mu \mathrm{mol} \mathrm{kg}{ }^{-1}$ for values less than $100 \mu \mathrm{mol} \mathrm{kg}^{-1}$ and $50 \mu \mathrm{mol} \mathrm{kg}{ }^{-1}$ for values larger than $100 \mu \mathrm{mol} \mathrm{kg}{ }^{-1}$. Also included are the isopycnal $\sigma_{\theta}=$ $25.8,26.6$ and $27.1 \mathrm{~kg} \mathrm{~m}^{-3}$. The isopycnal $\sigma_{\theta}=25.8 \mathrm{~kg} \mathrm{~m}^{-3}$ is representing the boundary between Tropical Surface Water and Central Water, the isopycnal $\sigma_{\theta}=27.1 \mathrm{~kg} \mathrm{~m}^{-3}$ the boundary between the Central Water and the Antarctic Intermediate Water in the North Atlantic. The grey shading is in $5 \mu \mathrm{mol} \mathrm{kg}{ }^{-1}$ steps for values less than $90 \mu \mathrm{mol} \mathrm{kg}^{-1}$.

Fig. 3: Distribution of dissolved oxygen in $\mu \mathrm{mol} \mathrm{kg}-1$ on a meridional section in the South Atlantic along about $5^{\circ} \mathrm{E}$ between $20^{\circ} \mathrm{S}$ and the equator in March 1995 from $R V$

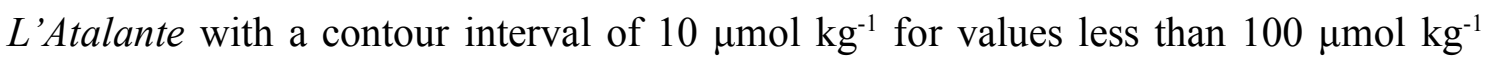
and $50 \mu \mathrm{mol} \mathrm{kg} \mathrm{kg}^{-1}$ for values larger than $100 \mu \mathrm{mol} \mathrm{kg}$. Also included are the isopycnal $\sigma_{\theta}=26.2,26.6$ and $27.05 \mathrm{kgm}^{-3}$. The isopycnal $\sigma_{\theta}=26.2 \mathrm{kgm}^{-3}$ is representing the boundary between Tropical Surface Water and South Atlantic Central Water, the isopycnal $\sigma_{\theta}=27.05 \mathrm{kgm}^{-3}$ the boundary between the South Atlantic Central Water and the Antarctic Intermediate Water in the South Atlantic. The grey shading is in $5 \mu$ mol $\mathrm{kg}^{-1}$ steps for values less than $90 \mu \mathrm{mol} \mathrm{kg}$.

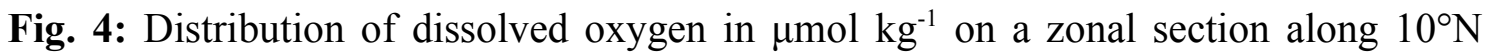
east of $160^{\circ} \mathrm{W}$ in April/May 1989 from $R V$ Moana Wave with a contour interval of 20 $\mu \mathrm{mol} \mathrm{kg} \mathrm{kg}^{-1}$ for values less than $50 \mu \mathrm{mol} \mathrm{kg}{ }^{-1}$ and $50 \mu \mathrm{mol} \mathrm{kg}{ }^{-1}$ for values larger than 50 $\mu \mathrm{mol} \mathrm{kg}$. Also included are the isopycnal $\sigma_{\theta}=25.5,26.6$ and $26.8 \mathrm{kgm}^{-3}$, the latter two are representing the Central Water/Intermediate Water boundary in the North and South 
Pacific. The grey shading is in $5 \mu \mathrm{mol} \mathrm{kg} \mathrm{kg}^{-1}$ steps for values less than $50 \mu \mathrm{mol} \mathrm{kg}$. The

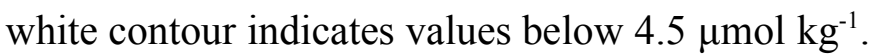

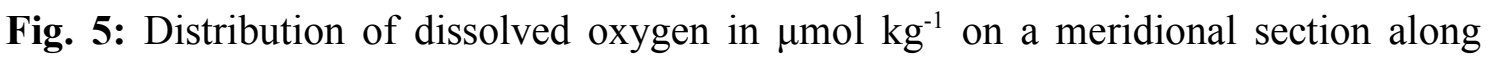
about $85^{\circ} \mathrm{W}$ south of $5^{\circ} \mathrm{N}$ and at about $90^{\circ} \mathrm{W}$ north of $5^{\circ} \mathrm{N}$ in March/April 1993 from

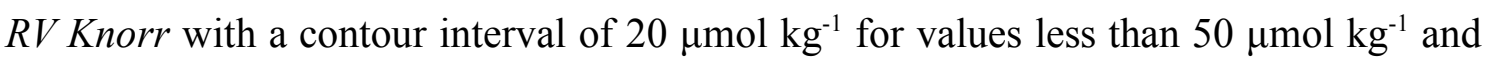

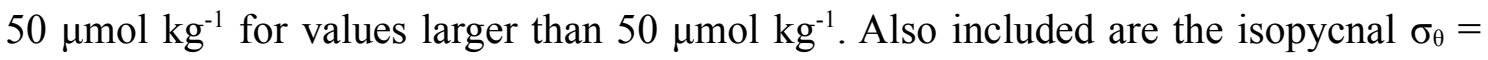
25.5, 26.6 and $26.8 \mathrm{kgm}^{-3}$, the latter two are representing the Central Water/Intermediate Water boundary in the North and South Pacific. The grey shading is

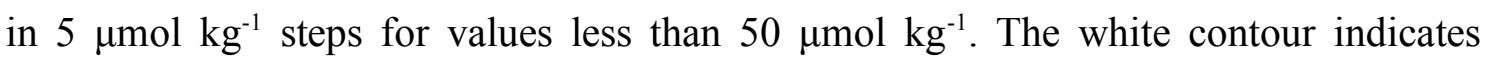
values below $4.5 \mu \mathrm{mol} \mathrm{kg} \mathrm{kg}^{-1}$.

Fig. 6: Conceptual view of the supply and consumption of oxygen. (left:) Interior ocean ventilation through a volume/oxygen flux through $\left(S_{a n n}\right)$ into an ocean volume $V_{\text {iso }}$ bounded by isopycnals $\sigma_{1}$ and $\sigma_{2}$. The annual net flux originates from the winter mixed layer base (broken line) in the outcrop region. The OMZ is located far away from the outcrop. (right:) While ocean transport redistribute the oxygenated water which stem from the outcrop, consumption reduces the oxygen content as expressed through an apparent oxygen utilization rate (aOUR) which is depth dependent.

Fig. 7: Volume of individual oceans in relation to oxygen content. Numbers are based on WHP-SAC density and oxygen data (Gouretski \& Jahnke, 1998). Only the ocean volume with density $<27.2 \mathrm{~kg} \mathrm{~m}^{-3}$ is considered.

Fig. 8: Apparent oxygen utilization rates for the Atlantic (left) and the Pacific (right) Oceans and nonlinear minimization fit to a logarithmic function. The rate is derived as the ratio of apparent oxygen utilization and CFC11 ages from the GLODAP data set. Gray dots indicate original data, black dots with error-bars indicate the $20 \mathrm{~m}$ depth bin averages values. The aOUR at $1500 \mathrm{~m}$ depth is assumed to be $0.1 \mu \mathrm{mol} \mathrm{kg}^{-1} \mathrm{y}^{-1}$ as suggested by CR-age data. See text for details on the data selection. The range of aOUR values assuming a $20 \%$ uncertainty are given with the two solid lines. 
Fig. 9: Volume (upper panels), and volume flux through subduction (lower panels) for density interval between 25.0 and $27.2 \mathrm{~kg} \mathrm{~m}^{-3}$ in $0.1 \mathrm{~kg} \mathrm{~m}^{-3}$ density bins. The colours indicate $\mathrm{OMZ}$ threshold density ranges of: minimum $\mathrm{O}_{2}$ (compare Table 1), $45 \mu \mathrm{mol} \mathrm{kg}$ -

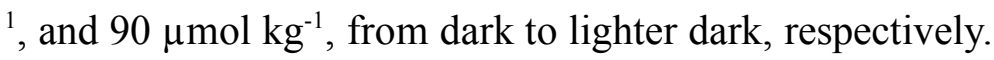

Fig. 10: Transit-time for the density interval $\sigma_{\theta}=25.0$ to $27.1 \mathrm{~kg} \mathrm{~m}^{-3}$ in $0.1 \mathrm{~kg} \mathrm{~m}^{-3}$ bins. Shading indicates density ranges of: minimum $\mathrm{O}_{2}$ (compare Table 1), $45 \mu \mathrm{mol} \mathrm{kg}^{-1}$, and $90 \mu \mathrm{mol} \mathrm{kg}{ }^{-1} \mathrm{OMZ}$ threshold, from dark to lighter dark, respectively. The uncertainty is based on a $20 \%$ error in subduction rates.

Fig. 11: Selected oxygen age distribution normalized to one in reference to the maximum value: (a) oxygen age distribution with a peak for youngest water and exponential decay of ages towards older waters (shape 1), typical for the upper density range in the Atlantic and South Pacific; (b) solitary peak oxygen age distribution (shape 2) as typical for a diffusion only system as in the North Pacific; (c) double (multiple) peak oxygen age distribution (shape 3) as for the lower Atlantic and South Pacific. For reference the average oxygen age $\left(\tau_{\mathrm{a}}\right)$ is indicated by the broken line, the turn-over time $\left(\tau_{0}\right)$ by the stippled line. Note, $\tau_{0}$ in case $b$ ) is infinite (no outcrop). The isopycnal is given on the right of the figure, the examples stem from the South Pacific (a), North Pacific (b) and North Atlantic (c).

Fig. 12: Contour of the normalized (maximum to one) age distribution in respect to outcrop density. The solid black line indicates the average oxygen age $\tau_{\text {a }}$ (volume integrated oxygen ages), the broken line indicates the turn-over time $\tau_{0}$ (based on subduction rates and volume of isopycnal). Uncertainty on turn-over time is based on $20 \%$ uncertainty in subduction rates. Oxygen ages are the average age from 20 repeat analysis while adding random noise of $20 \%$ to the aOUR values. 


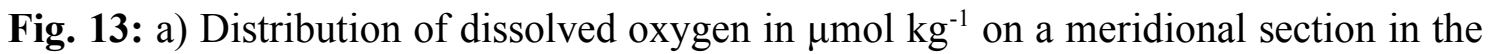
South Atlantic along about $28^{\circ} \mathrm{W}$ between $11.6^{\circ} \mathrm{S}$ and $2.5^{\circ} \mathrm{S}$ in May 2003 from $R V$ Sonne with a contour interval of $10 \mu \mathrm{mol} \mathrm{kg} \mathrm{kg}^{-1}$. The grey shading is in $10 \mu \mathrm{mol} \mathrm{kg}{ }^{-1}$ steps for values less than $180 \mu \mathrm{mol} \mathrm{kg}$. Overlain is the ADCP-derived velocity field with 10 $\mathrm{cm} / \mathrm{s}$ contour interval. The zero velocity is the thick solid line, negative (westward) velocities are shown as dashed lines, positive (eastward) velocities as solid lines. b) Depth averaged ADCP-derived velocity (solid line) and oxygen (broken line) between 200 and $500 \mathrm{~m}$ depth.

Fig. 14: WHP-SAC oxygen minimum (contours) in relation to: (a) Ekman induced upwelling (shaded) based on SODA (NCEP/NCAR) wind field average 1992-2001. For the equatorial region $\left(10^{\circ} \mathrm{N} / \mathrm{S}\right.$ of equator) the upwelling was calculated as the divergence of the upper layer velocity field. (b) Flow trajectories based on average horizontal advection between $\sigma_{\theta}=26.5$ and $27.2 \mathrm{~kg} \mathrm{~m}^{-3}$. The data was smoothed with a $4^{\circ} / 8^{\circ}$ latitude/longitude running mean. (c) Average (1. January 1997 to 31. August 2005) SeaWiFS Chlorophyll-a concentrations above average $\left(1.89 \mathrm{mg} \mathrm{m}^{-3}\right.$ between $65^{\circ} \mathrm{N}$ and $\left.65^{\circ} \mathrm{S}\right)$ is shaded. 


\section{Figures and Tables:}

Table 1

Summary of OMZ characteristics based on direct observations (GLODAP data set, Sabine et al. 2005) and a gridded climatology (WHP-SAC, Gouretski \& Jahnke, 1998).

Note, the Indian Ocean is given for reference but not discussed in this study.

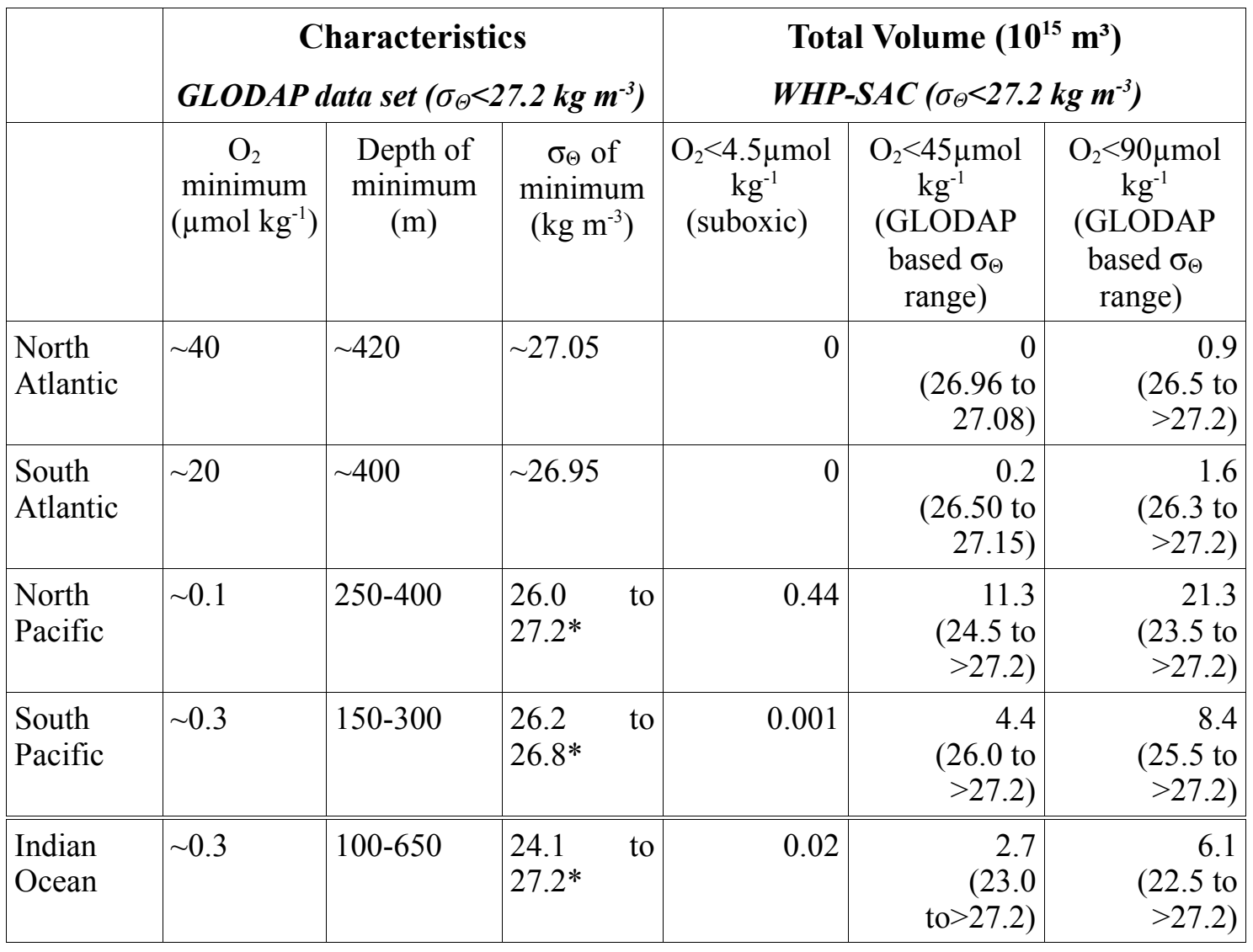

*using $1 \mu \mathrm{mol} \mathrm{kg}{ }^{-1}$ above and below the absolute minimum as threshold 
Table 2

Relative distribution of volume and ventilation/subduction in the Atlantic and Pacific Ocean based on 1992 to 2001 SODA 1.4 data (Carton, \& Giese, submitted) for the density range 25.0 to $27.2 \mathrm{~kg} \mathrm{~m}^{-3}$.

\begin{tabular}{|l|c|c|c|c|}
\hline & North Pacific & South Pacific & North Atlantic & South Atlantic \\
\hline \multirow{2}{*}{$\begin{array}{l}\text { Volume } \\
\left(146 \cdot 10^{15} \mathrm{~m}^{3} \text { total }^{*}\right)\end{array}$} & $28 \%$ & $44 \%$ & $13 \%$ & $15 \%$ \\
\cline { 2 - 5 } & \multicolumn{2}{|c|}{ Pacific: $72 \%$} & \multicolumn{2}{|c|}{ Atlantic: $28 \%$} \\
\hline $\begin{array}{l}\text { Subduction } \\
(152 \mathrm{~Sv} \text { total }\end{array}$ & $14 \%$ & $38 \%$ & $18 \%$ & $30 \%$ \\
\cline { 2 - 5 } & \multicolumn{2}{|c|}{ Pacific: $52 \%$} & \multicolumn{2}{|c|}{ Atlantic: $48 \%$} \\
\hline
\end{tabular}

* Note, Indian Ocean is not included 

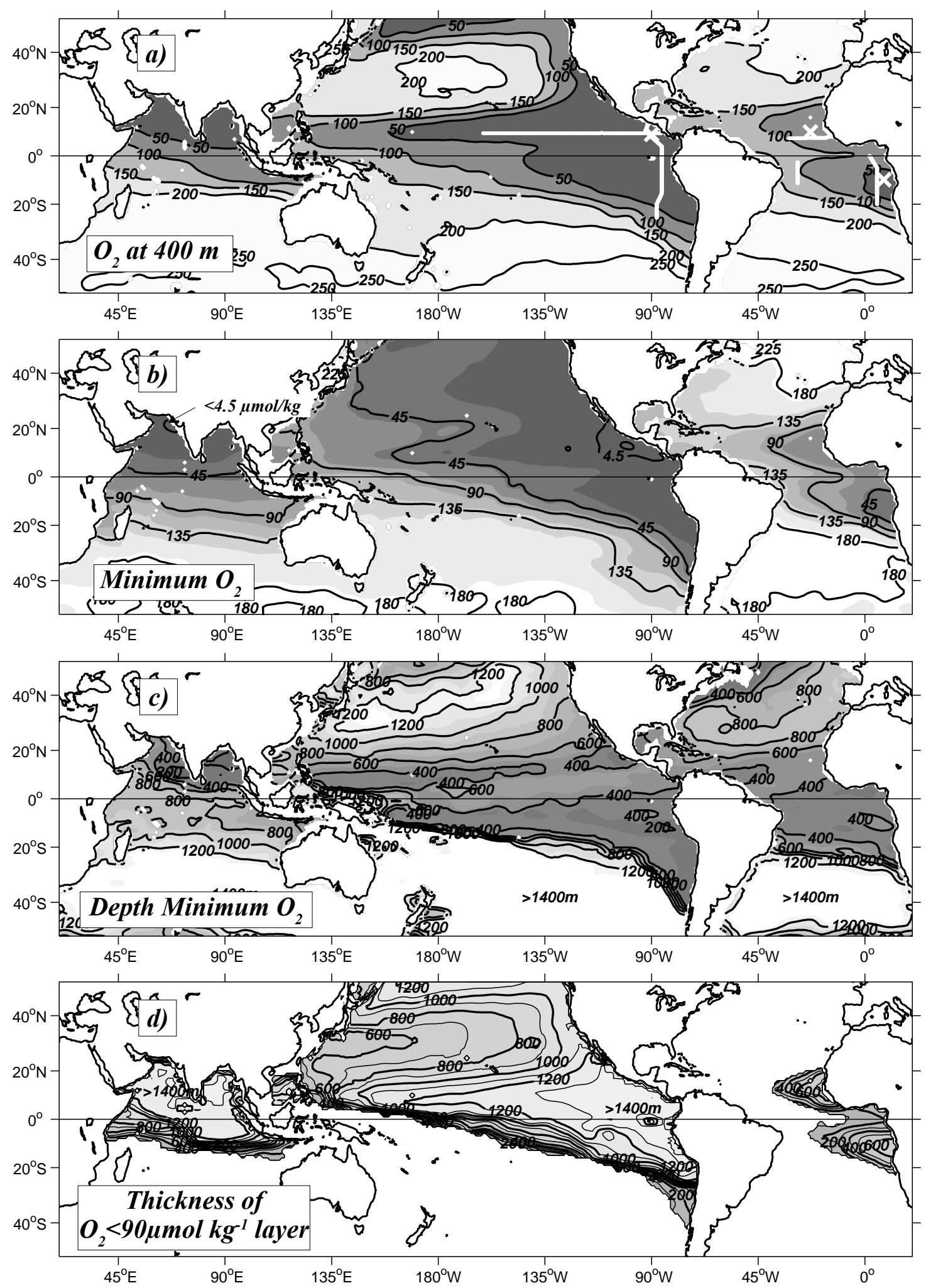

Figure 1: 


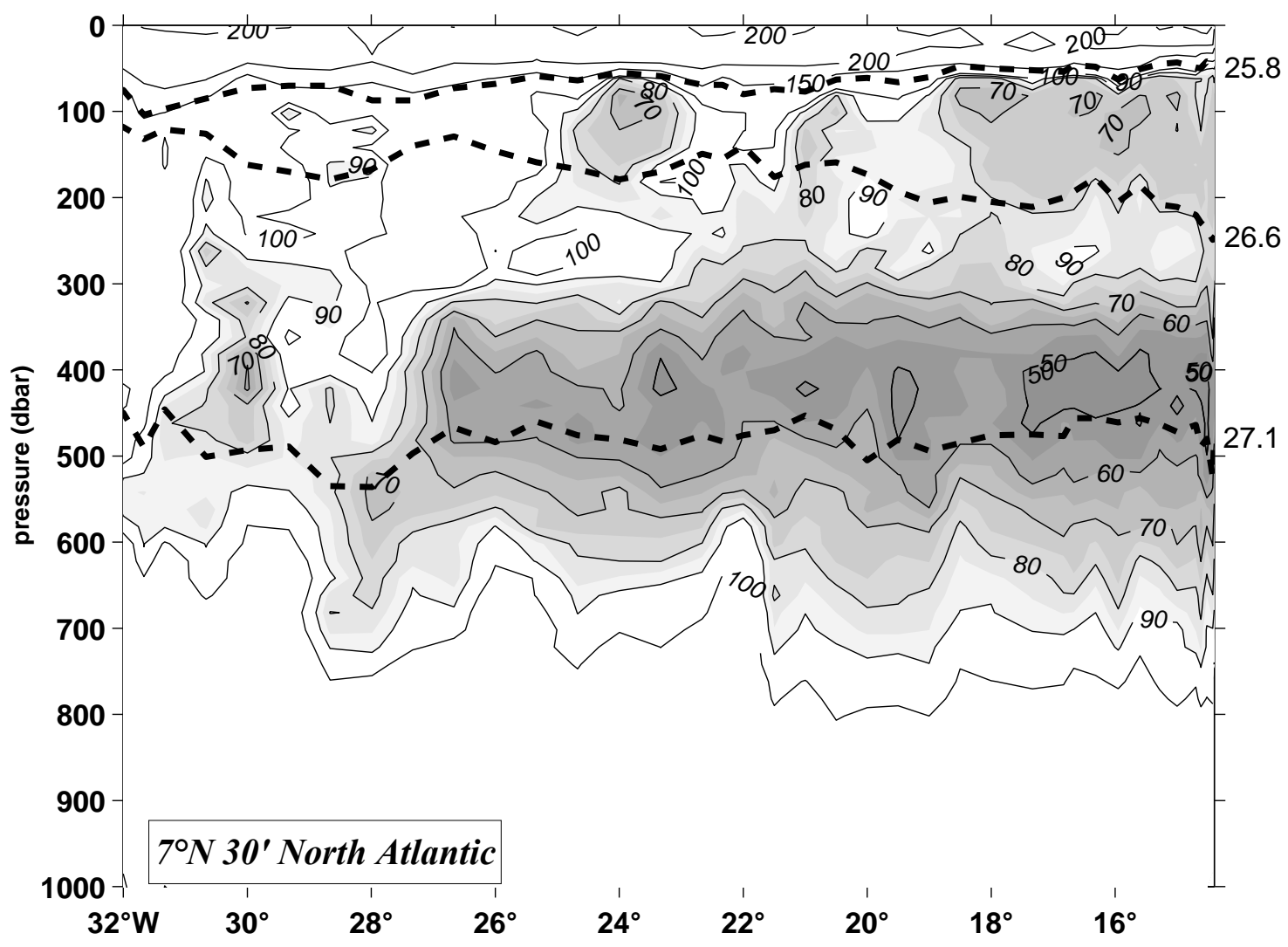

Figure 2: 


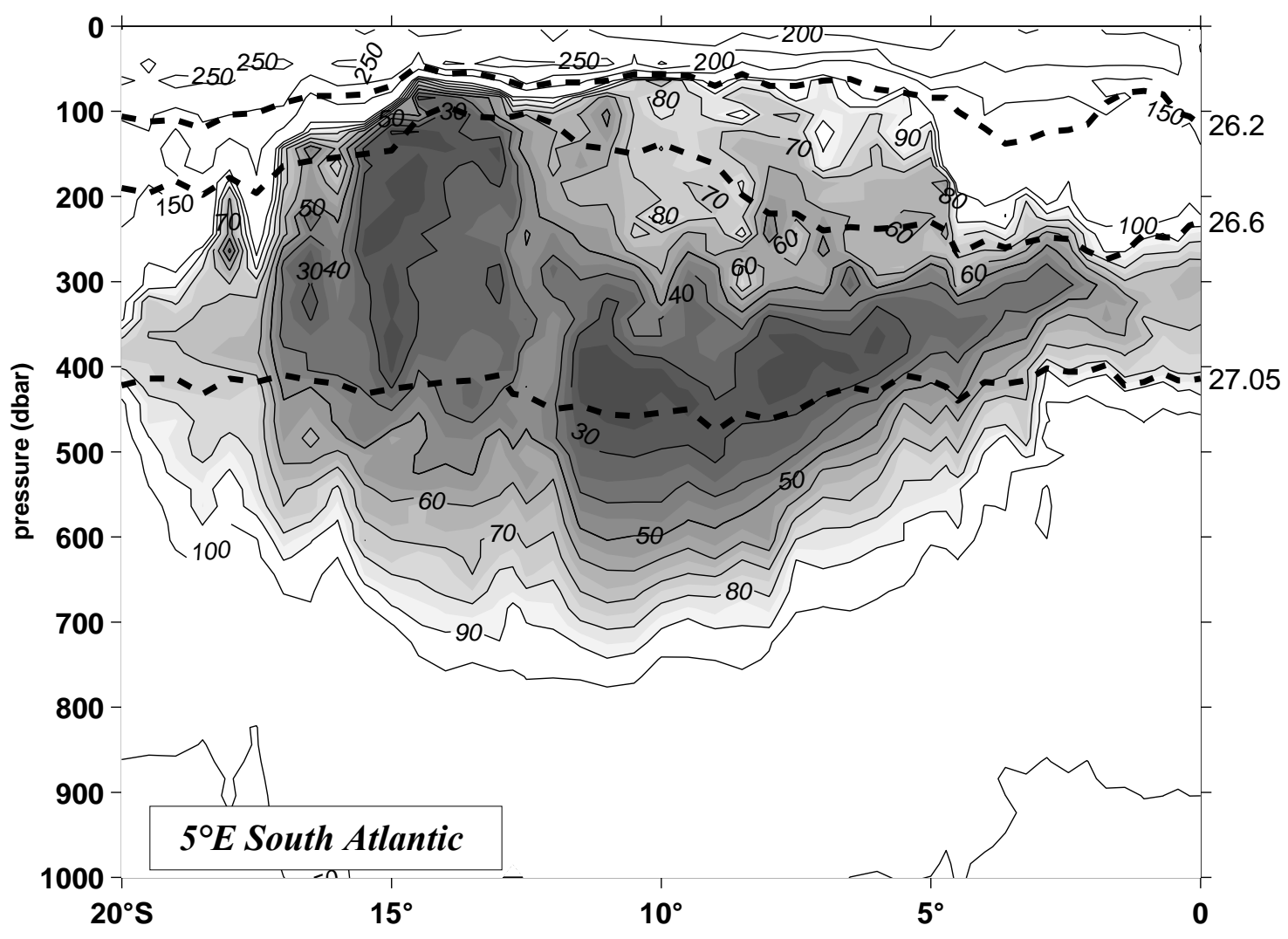

Figure 3: 


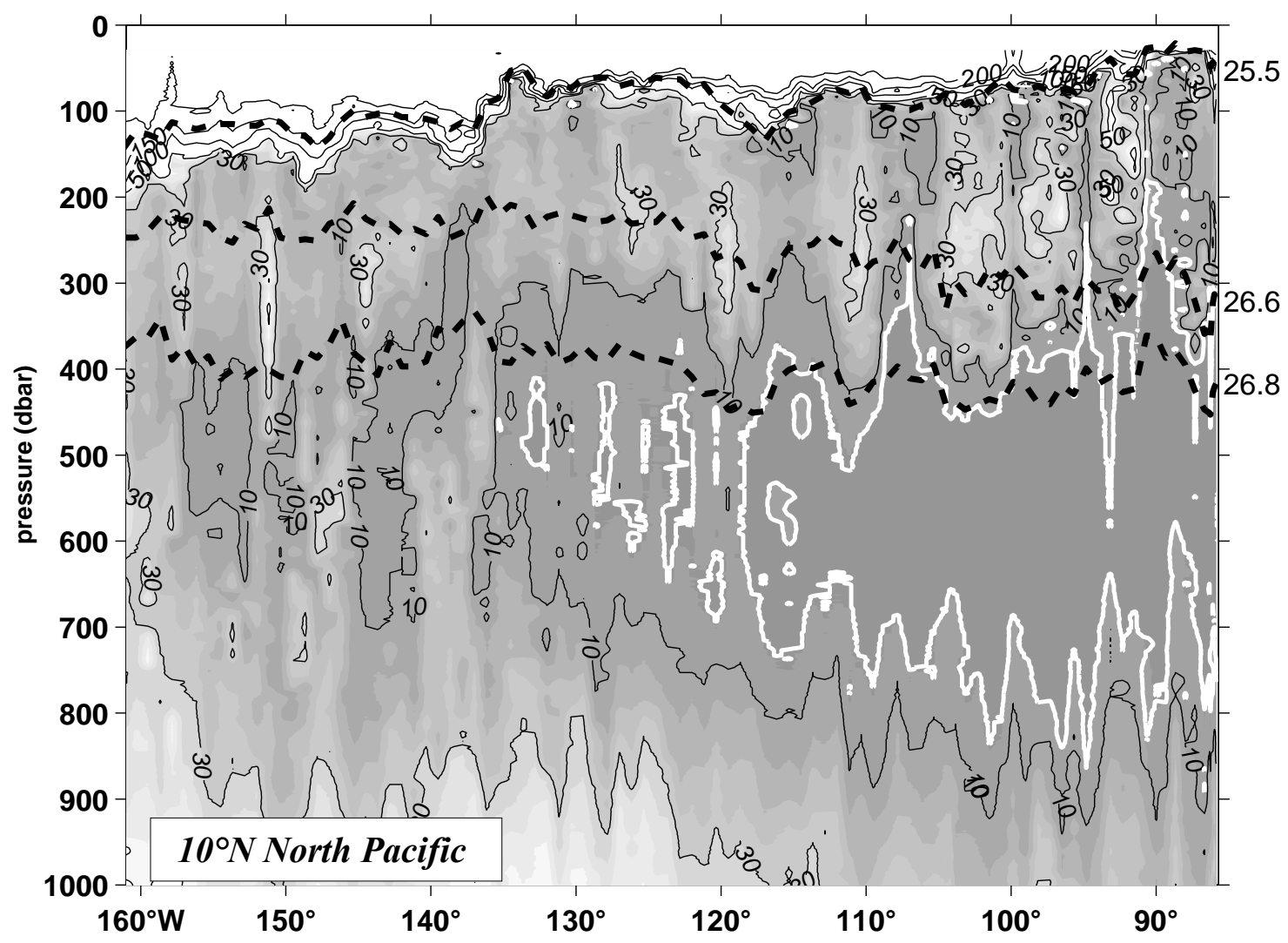

Figure 4: 


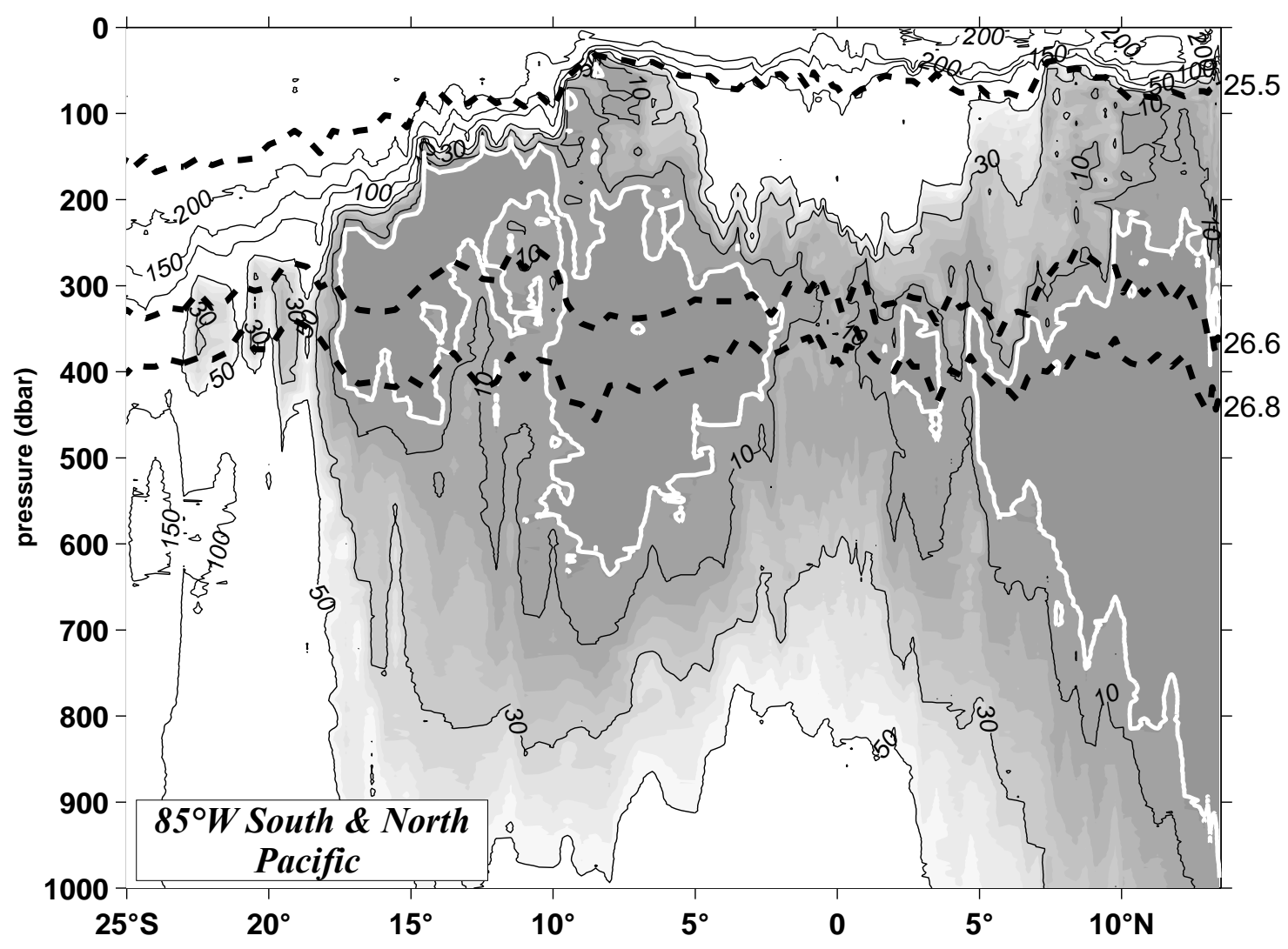

Figure 5: 


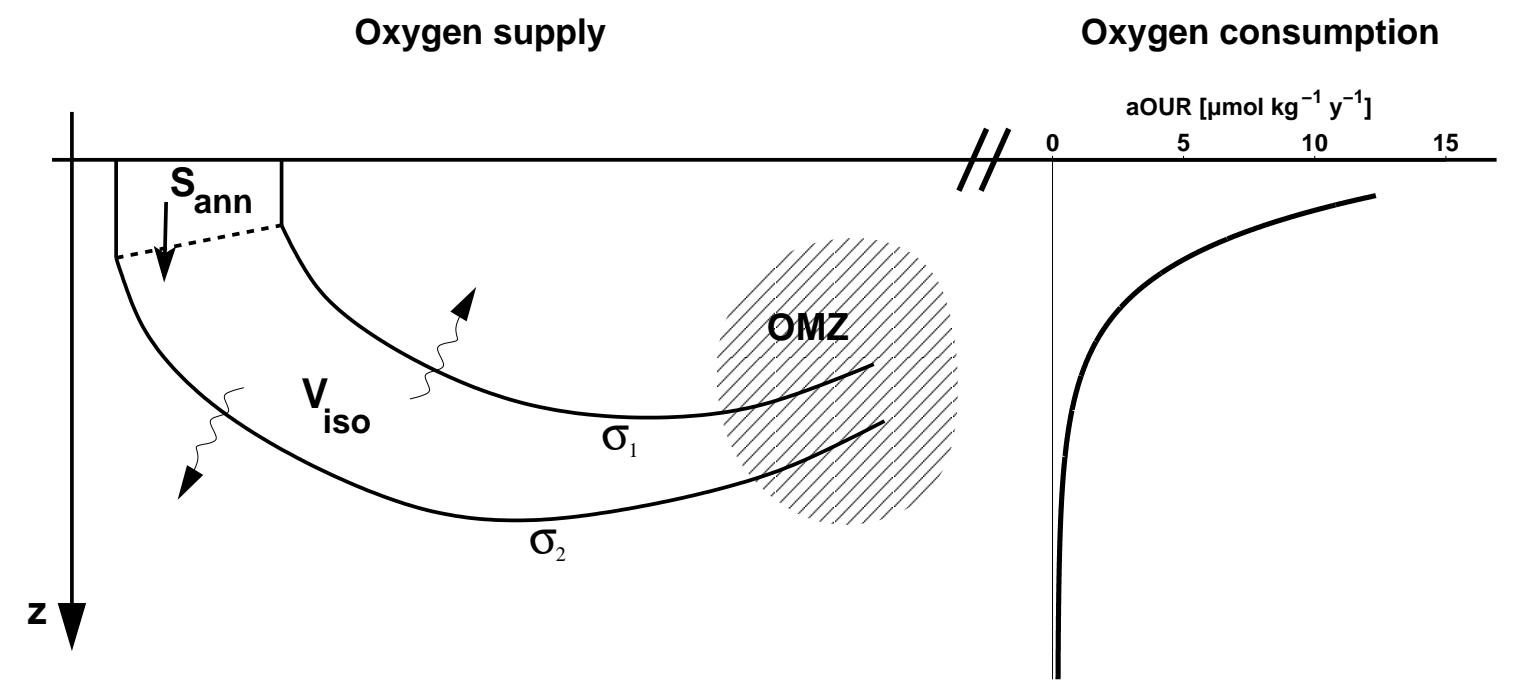

Figure 6: 


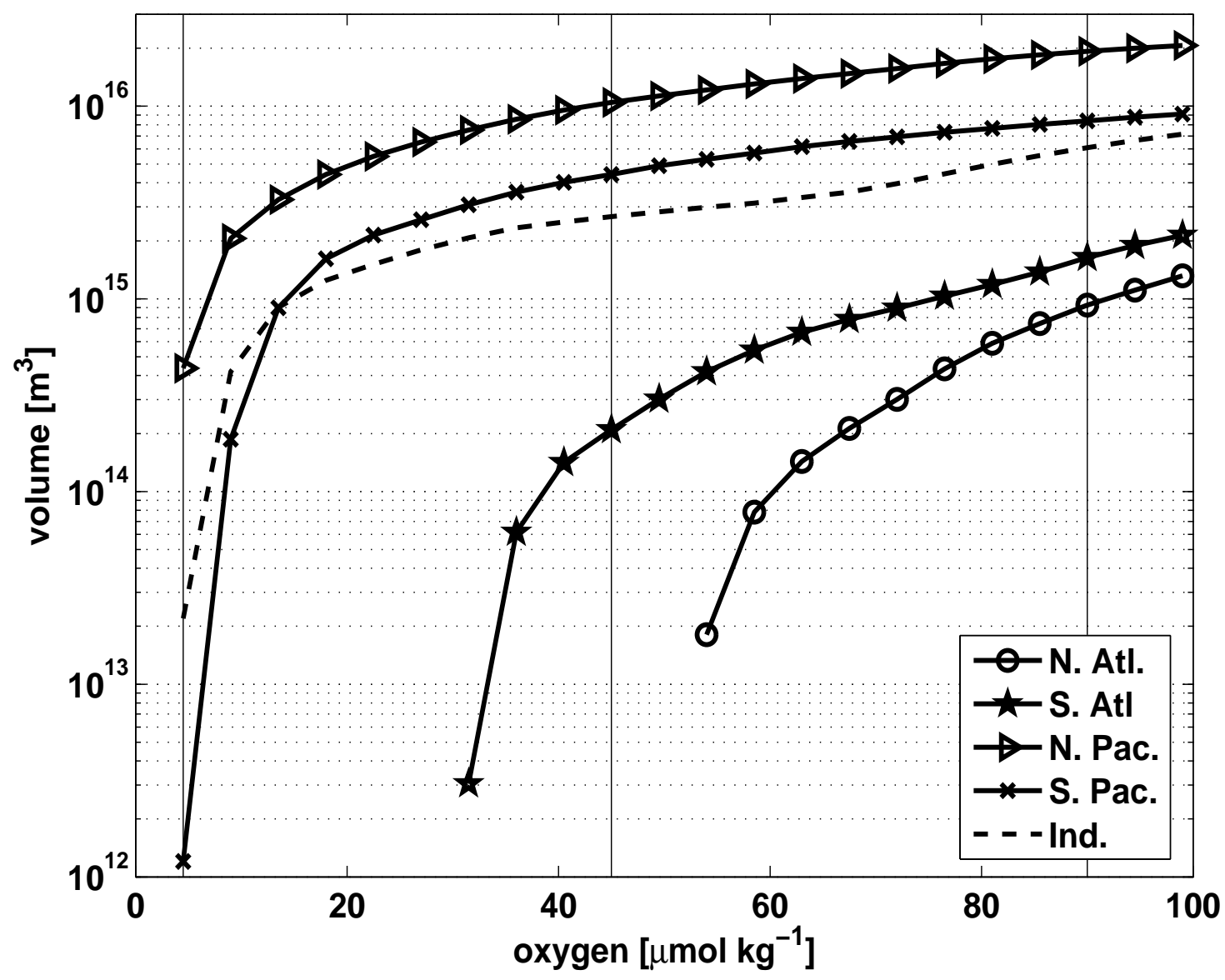

Figure 7: 

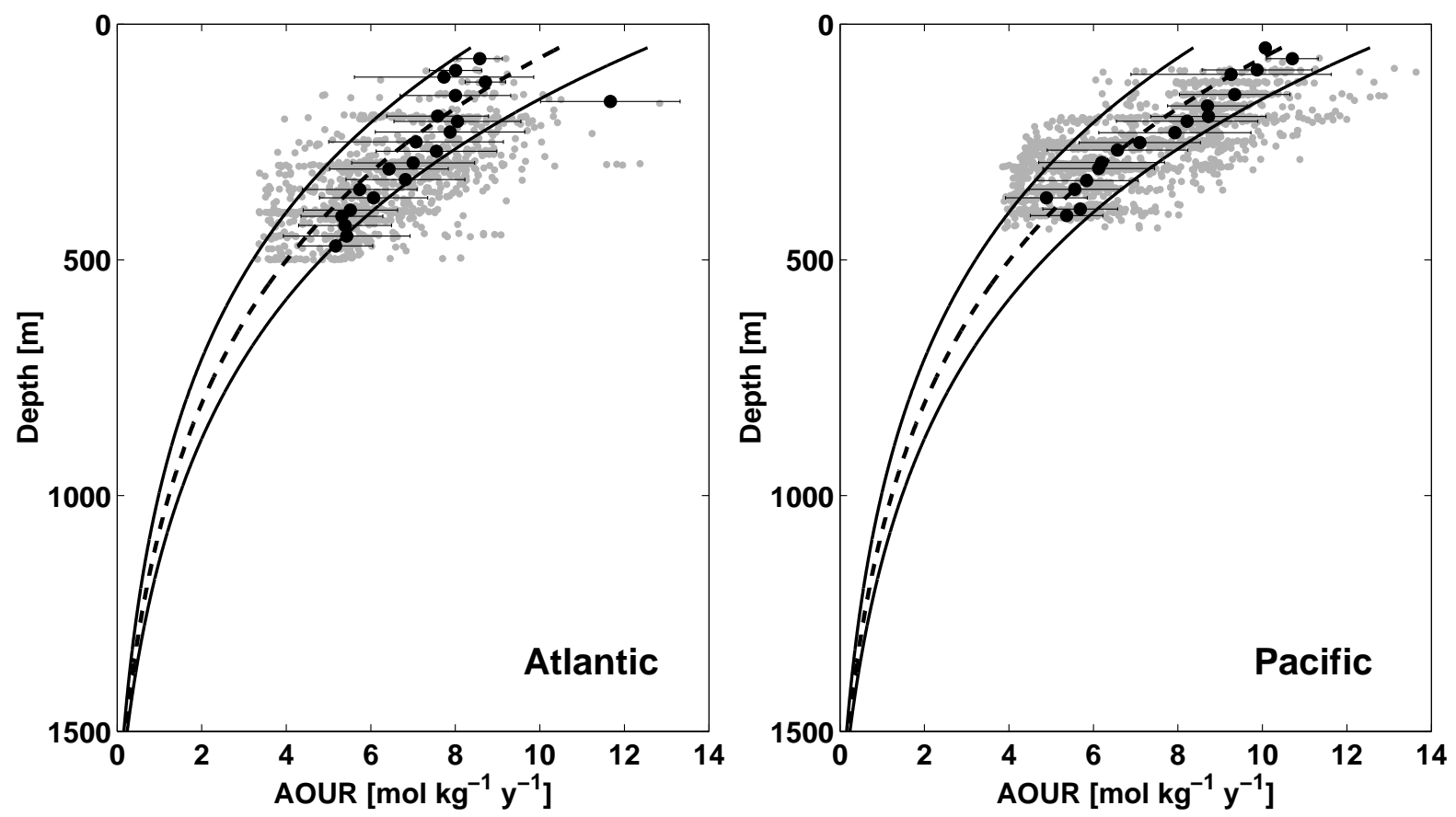

Figure 8: 

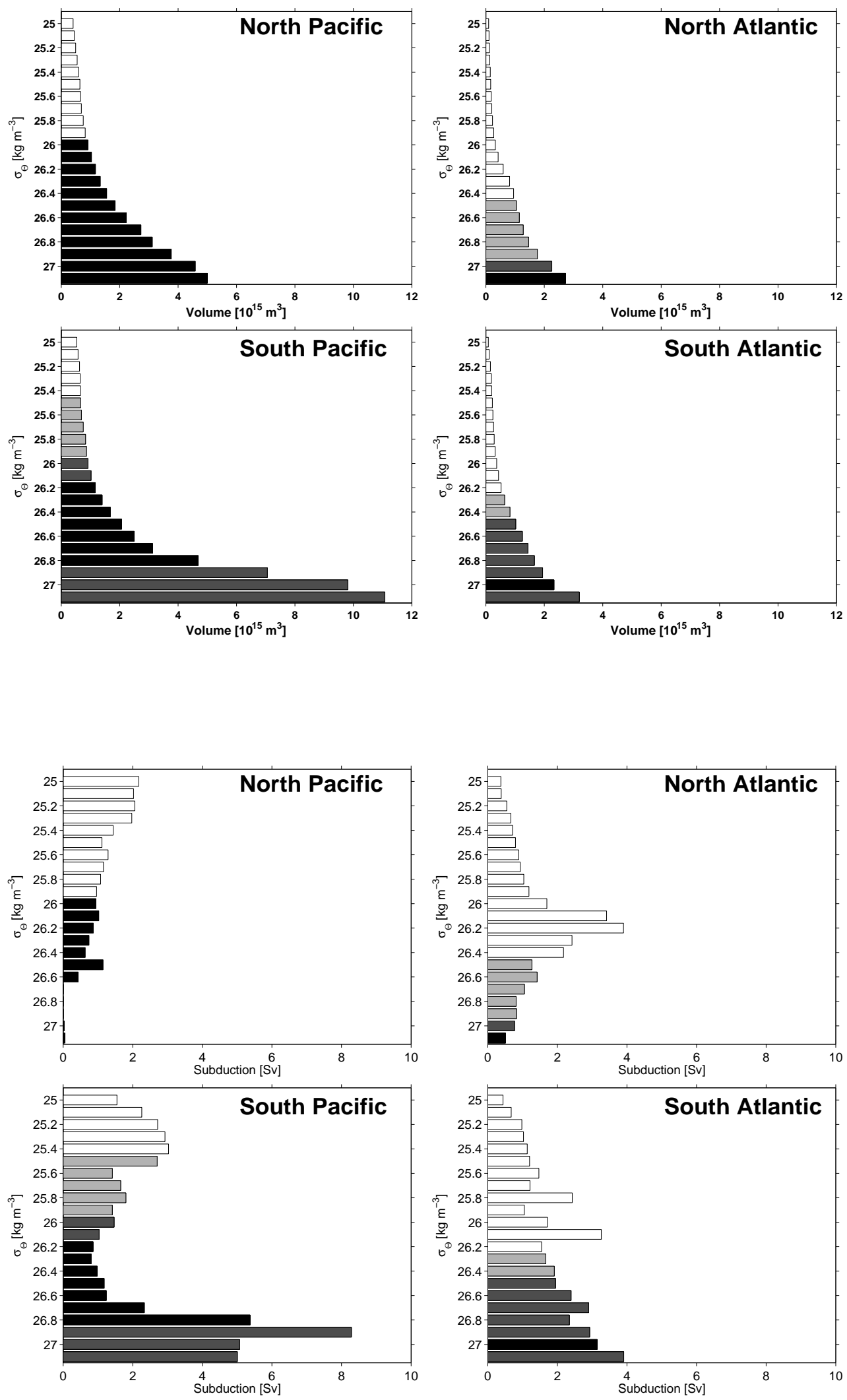

Figure 9: 

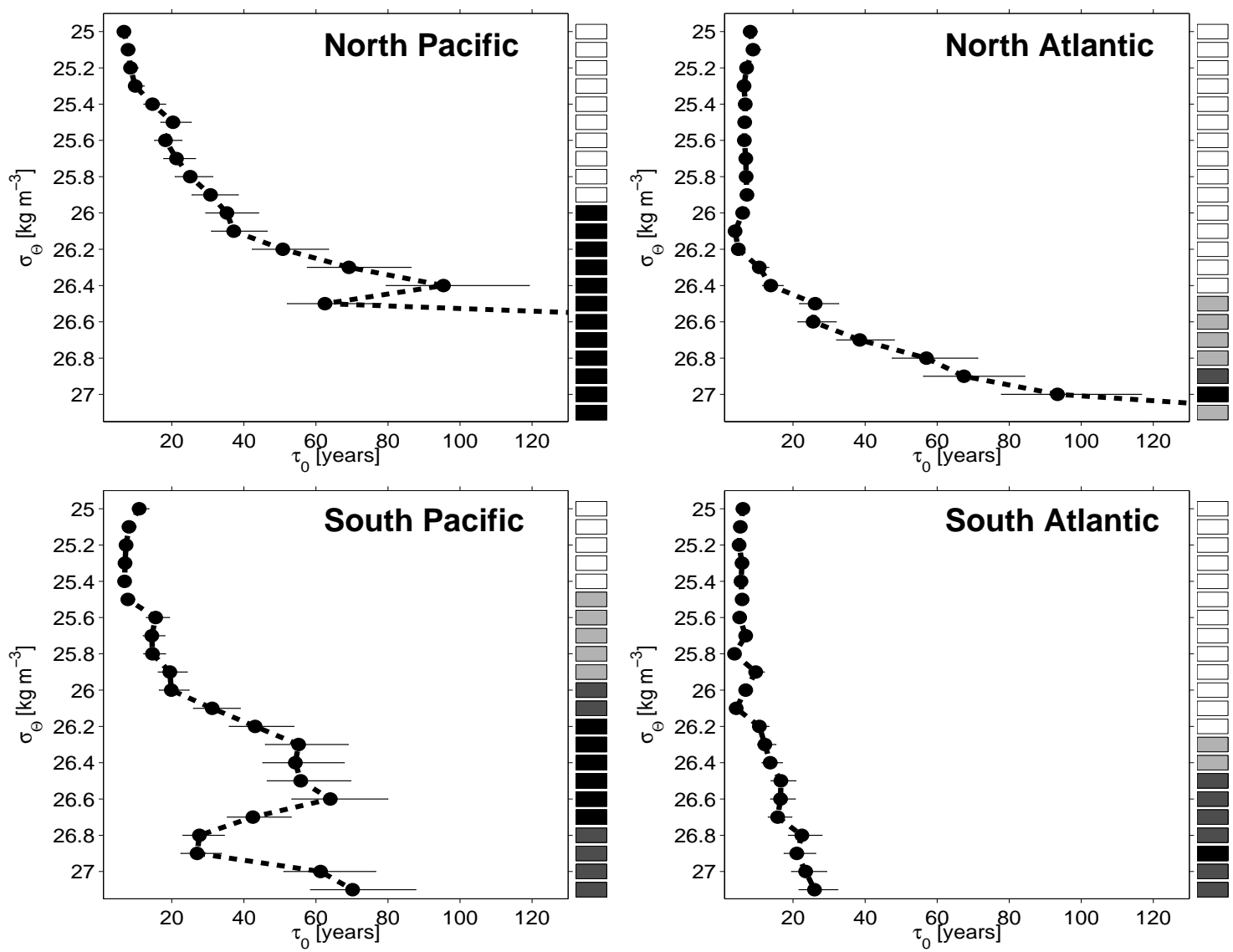

Figure 10: 

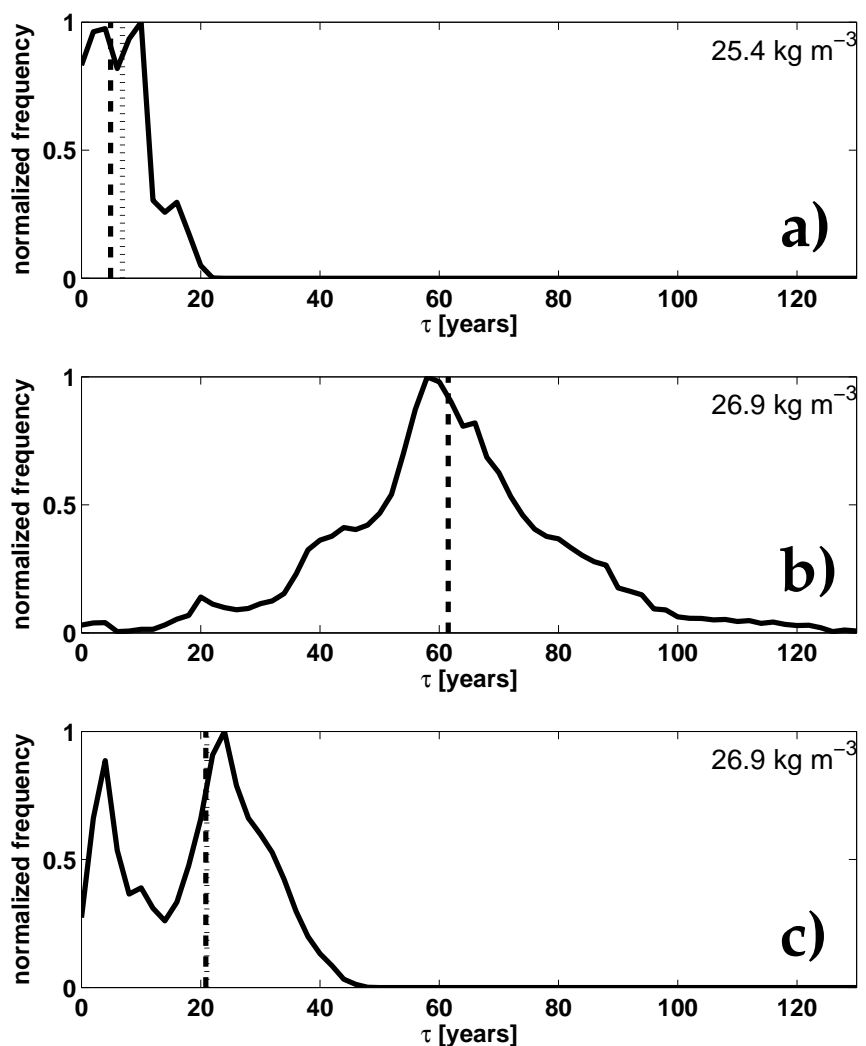

Figure 11: 

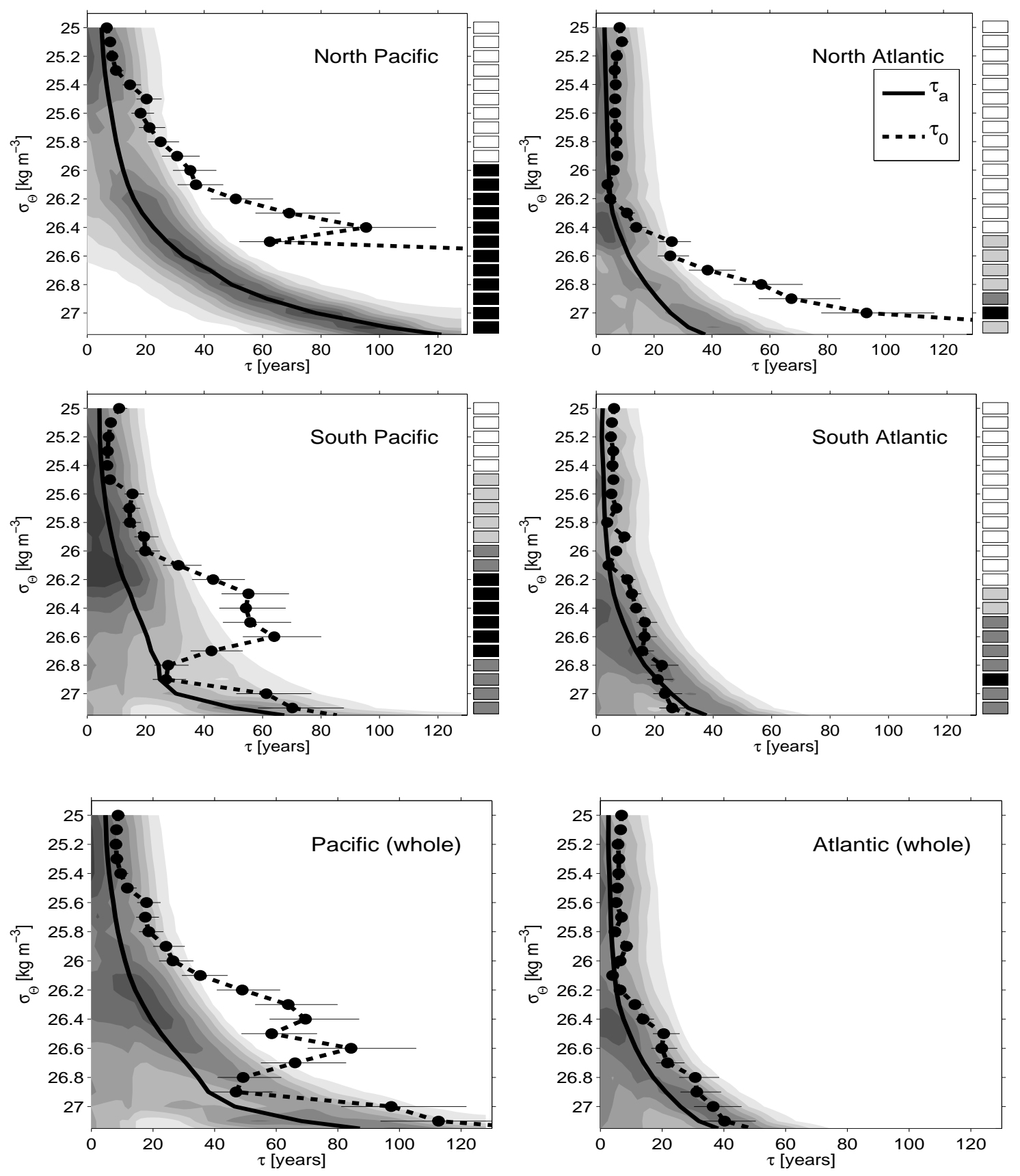

Figure 12: 

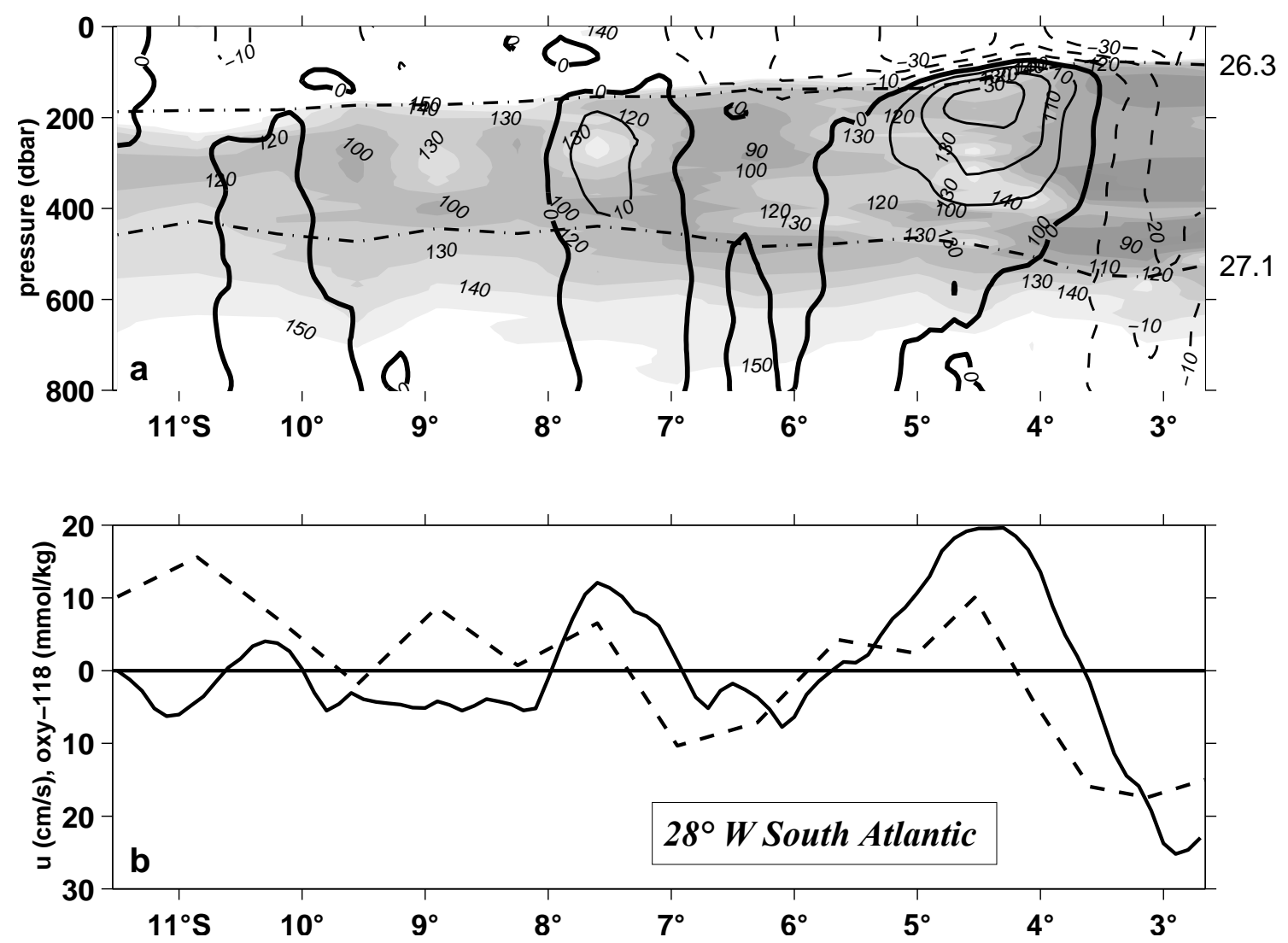

Figure 13: 

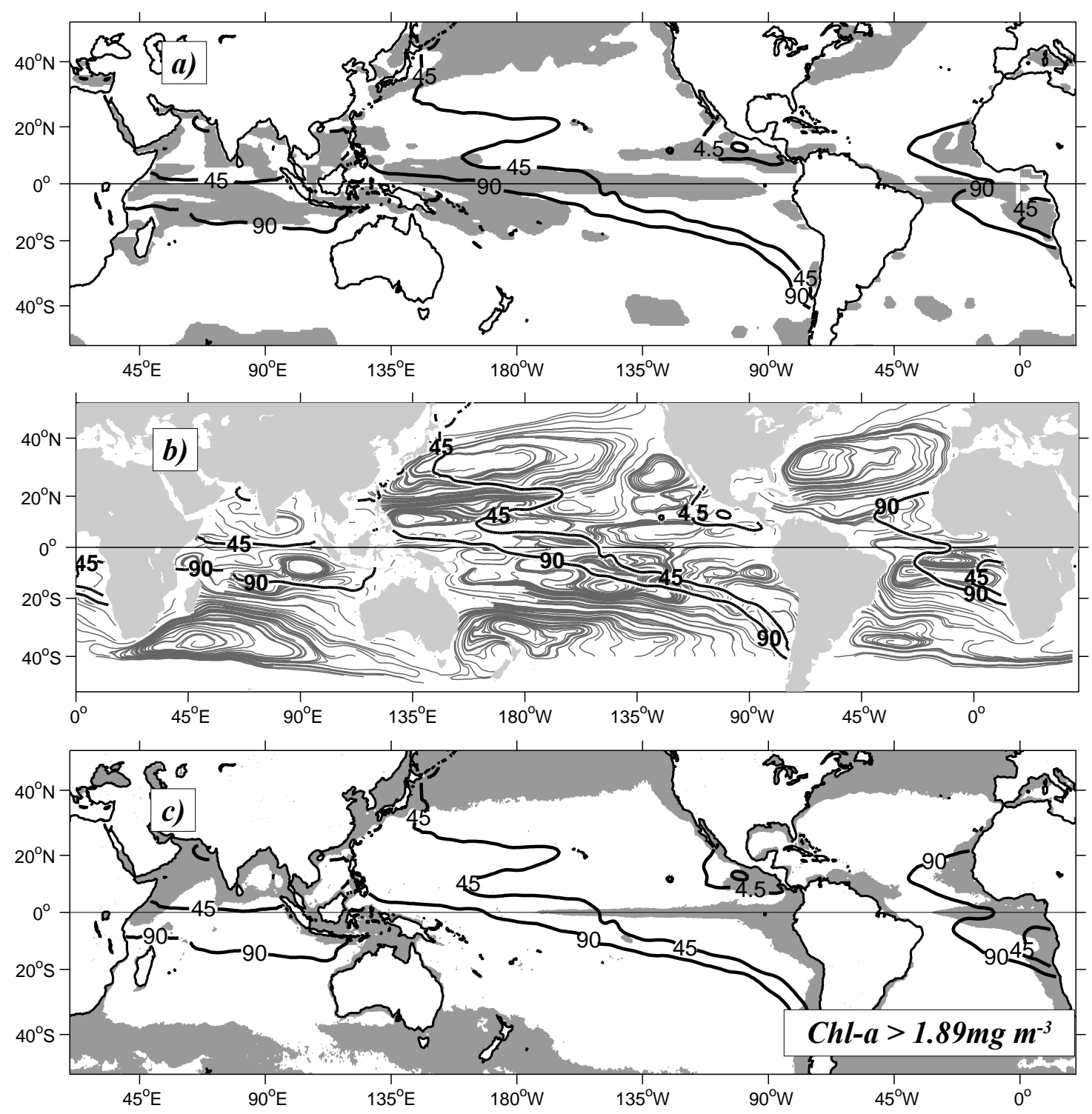

Figure 14: 